\title{
A política implícita no Brasil: retrospectiva e efeitos na competitividade nacional ${ }^{*}$
}

\section{Wallace Marcelino Pereira ${ }^{\dagger}$}

Resumo: A indústria é o setor chave para a promoção do desenvolvimento econômico, e para a geração de inovação, fazendo-se necessário o uso de política industrial para fomentar os setores mais importantes. No debate sobre política industrial e de C\&T\&I, pouca atenção tem sido dada à política implícita, e seus efeitos sobre o desempenho industrial e inovativo. O artigo objetiva avaliar a evolução da política implícita no Brasil, visando contribuir para o debate sobre a importância da coordenação entre objetivos de política macroeconômica, e os objetivos das políticas industrial e tecnológica. Ao se analisar os dispêndios do setor público, a evolução das principais variáveis de política macroeconômica, e o desempenho industrial e inovativo brasileiro, constata-se que ao longo dos últimos vinte anos o Brasil tem sofrido com a incapacidade de promover o desenvolvimento econômico sustentado, seja em razão da ausência da presença do Estado como indutor do desenvolvimento entre 1995 e 2003, seja pela ação mais direta do Estado a partir de meados dos anos 2000. Em última instância, o estágio atual da indústria e o nível da inovação brasileira é resultado, em parte, da ausência de coordenação adequada no manejo dos intrumentos implícitos com os objetivos de C\&T\&I, na medida que a oferta de crédito/financiamento público se concentrou em setores de menor intensidade tecnológica, bem como a trajetória desfavorável do câmbio contribuiu para limitar os resultados da política industrial e de C\&T\&I desenvolvidos recentemente.

\section{Palavra chave: Política Implícita - Política Industrial - Política de C\&T\&I - Desenvolvimento Econômico - Macroeconomia}

Abstract: Manufactury is the key sector for the promotion of economic development, and for the generation of innovation, making it necessary to use industrial policy to foster the most important sectors. In the debate on industrial policy and S\&T\&I, little attention has been given to the implicit policy, and its effects on industrial and innovative performance. The article aims to evaluate the evolution of implicit policy in Brazil, aiming to contribute to the debate on the importance of coordination between macroeconomic policy objectives, and the objectives of industrial and technological policies. When analyzing public sector expenditures, the evolution of the main variables of macroeconomic policy, and the Brazilian industrial and innovative performance, it is verified that over the last twenty years Brazil has suffered from the inability to promote sustained economic development, Either because of the absence of the State as an inducer of development between 1995 and 2003, or because of the more direct action of the State since the mid-2000s. Ultimately, the current stage of industry and the level of Brazilian innovation is a result, Partly because of the lack of adequate coordination in the management of implicit instruments with the S\&T\&I objectives, as the supply of public credit / financing was concentrated in sectors of lower technological intensity, as well as the unfavorable exchange rate trajectory contributed to limit the Results of industrial policy and S\& T\&I.

Key words: Implicit Policy - Industrial Policy - S \& T \& I Policy - Economic Development Macroeconomics

\section{Área 6.2 - Políticas de Ciência Tecnologia e Inovação}

JEL: 02

\footnotetext{
${ }^{*}$ Registra-se aqui agradecimentos às considerações da Professora Dra. Márcia Siqueira Rapini do CEDEPLAR/UFMG. Eventuais erros e omissões são de inteira responsabilidade do autor.

${ }^{\dagger}$ Doutorando em Economia pelo CEDEPLAR/UFMG.
} 


\section{Introdução}

O conceito de desenvolvimento econômico pode ser entendido como uma série de transformações na sociedade, e acima de tudo no processo de produção. Trata-se de mudança de estruturas e melhorias de indicadores econômicos, sociais e políticos, compreendendo necessariamente um fenômeno de longo prazo que implica o fortalecimento da economia nacional, a ampliação da economia de mercado, e a elevação geral da produtividade (SOUZA, 1999). Nesse sentido, a indústria é o setor chave para a promoção do desenvolvimento econômico, e para a geração de inovação, fazendo-se necessário o uso de política industrial para fomentar os setores mais importantes por meio da ação Estatal (KRUGMAN, 1989; CHANG, 1994). Para além disso, à política industrial cabe incluir a dimensão da inovação, do estímulo à ciência e tecnologia como forma de sustentar mudanças estruturais capazes de promover o desenvolvimento econômico. Nesse sentido, a inovação precisa ser pensada incluindo vários atores tais como universidades e governos, isto é, ser pensada em termos de Sistemas Nacionais de Inovação.

Assim posto, para a formulação e implementação de políticas voltadas para a inovação, faz-se necessário ter em mente a existência de uma diferenciação entre instrumentos e políticas de ciência e tecnologia explícitos e implícitos. Instrumentos explícitos "são aqueles que afetam diretamente as decisões vinculadas ao crescimento de uma capacidade local de C\&T, ao passo que instrumentos implícitos, são os que afetam de modo indireto, através dos efeitos e das consequências secundárias de outras decisões tomadas pela indústria, o governo e as próprias organizações de C\&T (SAGASTI, 1978).

Todavia, no debate sobre política industrial e de C\&T\&I, pouca atenção tem sido dada à política implícita, e seus efeitos sobre a estratégia industrial. Em outros termos, uma política industrial como estratégia de desenvolvimento implica a necessidade de compatibilizá-la com a política macroeconômica onde metas, normas e articulação de instrumentos precisam ser estabelecidos e coordenados em sinergia com a estratégia industrial (SUZIGAN e FURTADO, 2006). Caso ocorra ausência de coordenação entre os objetivos de política macroeconômica e os objetivos das políticas industrial e tecnológica, o desempenho da economia nacional pode ser comprometido (NASSIF, 2007). Dessa forma, objetiva-se avaliar a evolução da política implícita no Brasil, visando contribuir para o debate sobre a importância da coordenação entre objetivos de política macroeconômica, e os objetivos das políticas industrial e tecnológica. Neste sentido, o presente artigo encontra-se divido em 6 seções, sendo que nesta $1^{a}$ seção faz-se a introdução; na $2^{a}$ seção realiza-se uma breve revisão da literatura sobre política implícita e explicita; na $3^{\text {a }}$ seção é traçado um panorama da evolução recente da indústria brasileira; na $4^{\text {a }}$ seção analisa-se a dinâmica da economia brasileira em relação ao resto do mundo; na $5^{a}$ seção analisa-se a evolução da política implicita brasileira, e, por fim na $6^{\mathrm{a}}$ seção faz-se as considerações finais.

\section{Política Industrial e de $C \& T \& I$ : revendo a literatura}

O conceito de desenvolvimento econômico pode ser entendido como uma série de transformações na sociedade, e acima de tudo no processo de produção. Trata-se de mudança de estruturas e melhorias de indicadores econômicos, sociais e políticos, compreendendo necessariamente um fenômeno de longo prazo que implica o fortalecimento da economia nacional, a ampliação da economia de mercado, e a elevação geral da produtividade (SOUZA, 1999). Desse ponto de vista, o desenvolvimento econômico passa necessariamente pelo fortalecimento da indústria, considerada "o motor do crescimento" como exposto em Kaldor (1966), mas acima de tudo, para o caso dos países em desenvolvimento, um esforço na busca da industrialização. Em outros termos, o setor industrial desempenha papel ímpar no processo de criação de condições para o desenvolvimento. Justifica ao longo da história, praticamente todos os países que lograram estágios mais avançados de desenvolvimento tiveram na indústria, o meio principal para alcançar esse objetivo (PESSOTI e PESSOTI, 2009; RODRIK , 2010;2011).

A América Latina é o caso emblemático do esforço de industrialização, onde desde a década de 50 construiu-se um instrumental analítico, através da CEPAL, com vistas a subsidiar ações voltadas para a industrialização dos países latino-americanos como forma de capturar os frutos do progresso técnico, como pode ser observado nos escritos de Anibal Pinto, Raul Presbich, e Octavio Rodrigues, dentre outros. Tratase portanto, de subsidiar a formulação e implementação de políticas de desenvolvimento industrial. Segundo Guerra (1997), a definição de política industrial pode adquirir um caráter amplo ou um caráter 
restrito, onde o caráter amplo expressa-se em programas e medidas que afetam direta e indiretamente o setor industrial, e que envolveria elementos tais como: planejamento geral indicativo; formalização de objetivos e diretrizes; organização institucional específica; articulação com a política macroeconômica; adoção de medidas de fomento direcionadas para setores industriais específicos; investimento em infraestrutura econômica e de ciência e tecnologia, bem como o apoio ao sistema educacional. Nessa linha de pensamento destacam-se autores como Corden (1980), Johnson (1984) e Suzigan e Villela (1997).

$\mathrm{Na}$ definição mais restritiva de política industrial encontramos autores como Chang (1994), e Krugman (1989;1993). Para Krugman (1989) a política industrial corresponde à ação governamental no sentido de fomentar setores considerados como importantes para o crescimento econômico. Em Chang (1994) a política industrial é uma ação do Estado, voltada para indústrias e firmas específicas capazes de tornar mais eficientes o conjunto da economia. Nestes termos, como sugere Johnson (1984), a política industrial é em primeiro lugar resultado da vontade política, e posteriormente, uma questão técnica, de modo que, para garantir que a política industrial torne-se elemento primordial na política econômica, aquela deveria estar aos cuidados de um ministro de estado, do vice-presidente ou mesmo do próprio presidente da república (RODRIK, 2004).

A partir de uma perspectiva mais ampla, a política industrial se enquadraria e seria viabilizada sob uma condição específica que nos trabalhos de Fábio Erber denomina-se "convenção do desenvolvimento". Avançando no conceito keynesiano de convenção tradicionalmente conhecido, e incluindo a versão francesa de convenção, a "convenção do desenvolvimento" estabelece o que é desejável ou prioritário, e como a consecução desses objetivos seria viabilizada ou facilitada pela intervenção de política econômica (CARVALHO, 2014). Em outros termos, a "convenção do desenvolvimento" corresponde não só à constituição de um visão coletiva comungada entre todos, mas também a determinação de uma hierarquia de fins a serem executados com vistas à promoção do desenvolvimento por meio da política econômica.

Assim posto, em Erber e Cassiolato (1997) existem quatro "visões" de desenvolvimento industrial, a saber: $1^{\text {a }}$ ) A agenda neo-liberal radical que considera ser o mercado por meio do sistema de preços, capaz de respaldar e atender às necessidades de industrialização, sendo a política industrial um instrumento ineficiente. Cabe ao Estado apenas suprir o regime institucional e jurídico que favoreça a ação do mercado, e concomitantemente se atendo a intervir somente para estabelecer fundamentos macroeconômicos corretos que permita ampliação do mercados e seu bom funcionamento. Nesta perspectiva privilegia-se o macroeconômico, e inexiste portanto, razões para diferenciar setores e agentes econômicos; $2^{\mathrm{a}}$ ) A agenda neo-liberal reformista que se trata de uma variante da anterior, distinguindo-se da radical por conceder maior ênfase às imperfeições de mercado, e portanto, dando maior espaço à intervenção do Estado. A intervenção do Estado se faz necessária para sanar falhas de coordenação entre agentes econômicos, e nos mercado de fatores, sendo que a intervenção mais eficaz é a do tipo Market Friendly, centrada nos fundamentos da estabilidade econômica, fortes investimentos em capital humano, sistemas financeiros seguros e estáveis, poucas distorções no sistema de preços e abertura ao exterior. Como a agenda anterior, intervenções de natureza seletiva, de corte setorial ou por tipo de agente econômico são tidas como pouco eficazes, ou mesmo, contraproducentes; $3^{\mathrm{a}}$ ) A agenda neo-desenvolvimentista inspira-se principalmente na visão histórica do processo de formação do mercado, aliada à ênfase evolucionista que enfatiza a natureza cumulativa, mas sujeita a rupturas inerentes, do processo de desenvolvimento, onde fatores institucionais desempenham papel essencial. O Estado torna-se relevante na formulação de políticas de cunho neo-shumpeteriano baseadas na importância da inovação e difusão do progresso técnico. Destaca-se a ênfase na diferenciação entre agentes econômicos, e entre setores, levando-se em consideração o caráter coletivo das ações econômicas, expresso, por exemplo, nas relações estabelecidas dentro de cadeias produtivas e em redes, formais e informais, de empresas. Assim, esta perspectiva é predominantemente micro e mesoeconômica (nível de setores e cadeias produtivas), mas carente de uma perspectiva de dinâmica macroeconômica de curto prazo, que permita articulação entre medidas de estabilização, e medidas de política industrial, e; $4^{\mathrm{a}}$ ) A visão social democrata que diferentemente das demais agendas cuja preocupação fundamental é econômica, tem como seu objetivo principal sanar, mesmo que parcialmente os problemas sociais. $\mathrm{O}$ foco reside nas questões de emprego e oferta de serviços essenciais à população de baixa renda, notadamente saúde, educação, e transporte urbano, em que o Estado deve exercer sua intervenção. Como a agenda neo-desenvolvimentista, esta agenda é fortemente setorializada, e com 
forte conteúdo regional, de modo que a participação dos governos locais é crucial para o sucesso dessa agenda.

No que tange especificamente à política industrial, a vertente neoliberal, ou mais ortodoxa, considera que as políticas industriais, no limite, devem ser utilizadas para corrigir falhas ou imperfeiçoes de mercado, quando existirem, e que devem ser de natureza horizontal, isto é, não seletiva em termos de setores ou atividades para evitar a formação de comportamento do tipo rent-seeking (SUZIGAN e FURTADO, 2006; REINER e STARITZ, 2013). Além disso, critica também a incapacidade do Estado em saber qual, ou quais setores terão sucesso futuro, isto é, a ineficiência do Estado em escolher os setores vencedores ou campeões nacionais em detrimento do mercado (SUZIGAN E FURTADO, 2006; REINER e STARITZ, 2013). A diretriz portanto é que, o Estado deva agir no sentido de facilitar a esfera econômica, melhorando a infraestrutura, favorecendo a desregulamentação, fornecendo incentivos fiscais e financeiros, garantindo direitos de propriedade e criando um ambiente favorável aos investimento e aos negócios (REINER e STARITZ, 2013).

Por outro lado, a temática da política industrial voltou à baila nas discussões governamentais, e em instituições multilaterais (AGHION et al. 2011; REINER, 2012). Os argumentos se baseiam nas abordagens estruturalista e neo-estruturalista, onde a mudança estrutural é um fenômeno capaz de promover o desenvolvimento, subsidiado pelo setor industrial como o responsável pelo progresso tecnológico e geração de inovação (CHANG 2012; RODRIK 2010). À política industrial portanto, cabe incluir a dimensão da inovação, do estímulo à ciência e tecnologia como forma de sustentar mudanças estruturais capazes de promover o desenvolvimento econômico. Desta feita, inovações podem ser definidas como novas criações de significado econômico e social, de natureza material ou intangível, e que podem ser divididas basicamente em inovação de produtos e processos (EDQUIST,1999; BORRÁS e EDQUIST, 2013). Para Pacheco \& Almeida (2013) as empresas inovam de forma diferente, onde podem desenvolver produtos, modificar e os adaptar às necessidades de seus clientes, ou podem criar novos clientes, inventar novos modelos de negócios, mudar suas formas de gestão e cultura corporativa, visando buscar eficiência nos processos produtivos, na comercialização, no financiamento. Desse modo, o caráter inovativo é fortemente caracterizado pela incerteza, sendo que Rodrik (2010) acevera sobre a importância do Estado como o agente capaz de garantir apoio, e minimizar ou impedir que investimentos em inovação venham a fracassar.

Nestes termos, garantido o apoio estatal contra a incerteza, a preocupação reside no problema da capacidade de impor disciplina, ou em outros termos, estruturar um sistema de incentivos baseado no desempenho, dado que a existência de política industrial por si só não garante desenvolvimento (CHANG, 2011; REINER e STARITZ, 2013). Desta forma, em última instância como apontou Rodrik (2008), o foco da política industrial não deve estar mais tão centrado no "porque", mas em "como" conduzir a política industrial de forma adequada. Por essa razão, como apontam Suzigan e Furtado (2006), o estabelecimento de disciplina é vital em uma estratégia industrial impulsionada pela inovação, e por transformações tecnológicas com mudanças estruturais de empresas e indústrias.

Outra dimensão do "como" fazer a política industrial, com enfase na inovação, reside em como incluir e articular vários atores tais como universidades, empresas e governos, isto é, ser pensada em termos de sistemas nacionais de inovação. Nestes termos, Sistema Nacional de Inovação - SNI "é uma construção institucional, produto de uma ação planejada e consciente, ou de um somatório de decisões não planejadas e desarticuladas, que impulsionam o progresso tecnológico em economias capitalistas complexas" (ALBUQUERQUE, 1996, pg. 57). Logo, por ser o produto de uma ação planejada, corresponde ao fruto de uma política de inovação, "que compreende todas as ações combinadas que são empreendidas por organizações públicas que influenciam os processos de inovação" (BORRÁS e EDQUIST, 2013, pg. 1513). Desse modo, para Cassiolato \& Lastres (1998) o enfoque em termos de sistema de inovação já traz consigo duas orientações de política embutidas, quanto às novas formas de promoção à inovação: (i) que o processo inovativo, assim como as políticas para estímulo do mesmo, não podem ser vistos como elementos isolados de seus contextos nacional, setorial, regional, organizacional, institucional; e portanto, (ii) a importância de se focalizar a relevância de cada subsistema envolvido, assim como as articulações entre estes e entre agentes (CASSIOLATO e LASTRES, 1998, pg.16).

Assim posto, a concepção da necessidade de se formular e implementar políticas de inovação de forma não isolada nos remete à constatação de Sagasti (1978) em seu estudo "Ciência e Tecnologia para 
o desenvolvimento: informe comparativo central do projeto STPI'. Nele, o autor postular uma diferenciação entre instrumentos e políticas de ciência e tecnologia explícitos e implícitos, onde os primeiros "são aqueles que afetam diretamente as decisões vinculadas ao crescimento de uma capacidade local de C\&T, ao passo que os segundos, são os que afetam de modo indireto através dos efeitos e das consequências secundárias de outras decisões tomadas pela indústria, o governo e as próprias organizações de C\&T. Tendo-se em vista o considerável peso e a influência dos instrumentos implícitos, os mesmos limitam o impacto potencial dos instrumentos explícitos" (SAGASTI, 1978, pg. 30).

Ao encontro da proposição de Sagasti (1978), Rattner (1981) ao discutir e analisar as políticas tecnológicas de alguns países da América Latina, realizou a seguinte distinção, a saber: a) política tecnológica explícita, é tal como manifesta em documentos e pronunciamentos oficiais, implicando certo grau de normalização do comportamento tecnológico das empresas e dos órgãos do poder público. A política tecnológica explícita é manifesta pela criação de uma infra-estrutura visando à geração e/ou à adaptação de tecnologias. A nível institucional, surgem órgãos como o Conselho Nacional de Ciência e Tecnologia, Ministérios e Secretarias Estaduais, Centros de Pesquisa e Desenvolvimento, etc. Ademais, as atividades desses órgãos são caracterizadas pela elaboração de planos e programas setoriais e regionais de desenvolvimento científico e tecnológico, acompanhados por esquemas elaborados de alocação e distribuição de recursos financeiros; b) a política tecnológica implícita refere-se aos efeitos produzidos por planos, programas e diretrizes que não pertencem às atividades e funções científico-tecnológicas. São, geralmente, consequência de diretrizes e decisões tomadas em outras esferas da vida sócio-política (na economia, nas áreas de educação e cultura, relações e comércio exterior, etc.), porém, com profundo impacto sobre o comportamento tecnológico das empresas (RATTNER, 1981, pg. 17).

No que tange à política implícita, Rapini (2013) expõe que uma política implícita é a política macroeconômica onde medidas fiscais e monetárias são importantes para "despertar o empreendedor", e incentivar a inovação e o crescimento sustentado. Assim, uma política industrial como estratégia de desenvolvimento, implica a necessidade de compatibilizá-la com a política macroeconômica onde metas, normas e articulação de instrumentos precisam ser estabelecidos e coordenados em sinergia com a estratégia industrial (SUZIGAN e FURTADO, 2006). Em outros termos, caso ocorra ausência de coordenação entre os objetivos de política macroeconômica, e os objetivos das políticas industrial e tecnológica, o desempenho da economia nacional pode ser comprometido (NASSIF, 2007).

Isso se deve pelo fato de que, a política macroeconômica pode ser antagônica a uma estratégia de desenvolvimento baseada em política industrial quando analisamos os dois preços básicos da economia juros e câmbio e o nível e estrutura de tributação (SUZIGAN e FURTADO, 2006). Dependendo da intensidade do ajuste macroeconômico de curto prazo, a política industrial pode ser inviabilizada (CASSIOLATO e LASTRES, 1998;2000). Em outros termos, "the more disturbance there is on the macroeconomic side, the more industrial policy is likely to become short-term oriented, to flounder around, a tool in political and economic crisis management" (CORDEN, 1980, pg. 183). Nessa perspectiva, considerando as principais variáveis de política econômica (juros e câmbio) Coutinho (2005) define quatro tipos de regimes macroeconômicos, a saber: 1) benignos que correspondem àqueles que combinam taxas de juros baixas com taxas de câmbio relativamente subvalorizadas; 2) malignos, que apresentam taxas de juros elevadas e taxas de câmbio sobrevalorizadas; 3) semi-benigno, onde ocorre a coexistência de taxas de juros baixas e câmbio sobrevalorizado, e; 4) semi-maligno caracterizado pela coexistência de taxas de juros altas e taxa de câmbio subvalorizada.

\section{Evolução recente da indústria brasileira: breve panorama}

A atual dinâmica da indústria brasileira pode ser entendida a partir da década de 80 , também chamada de década perdida. Este período, conforme Carneiro (2002) expõe, caracterizou-se pela crise da dívida, e a piora dos termos de troca comercial com extremo racionamento do financiamento externo, significando por sua vez, na transferência de recursos externos para o exterior em razão do pagamento da dívida externa. Além disso, o período também foi marcado pela fragilidade do setor público, pelo endividamento interno, e perda de dinamismo do setor produtivo estatal. Assim, Carneiro (2016) aponta a combinação de três fatores em intensidades distintas para explicar o encarecimento do investimento: a desvalorização real do câmbio, o aumento da taxa de juros e os ciclos econômicos recessivos. 
Além dos aspectos conjunturais, Suzigan (1991) expõe que a estrutura industrial brasileira foi constituída por meio de políticas que continuamente proporcionaram níveis elevados de proteção à indústria no mercado interno. Adicionalmente, destaca-se que o apoio ao desenvolvimento tecnológico foi limitado à aquisição de capacidade para produzir, de modo que em fins de 70 , e princípios dos 80 , a estrutura industrial brasileira apresentava elevados graus de integração intersetorial e de diversificação da produção, muito embora, com insuficiente desenvolvimento tecnológico, ineficiências técnicas e econômicas específicas que em última instância, implicaram na limitação da sua competitividade, inexistência de qualquer padrão nítido de especialização, e pouca integração com o mercado internacional (SUZIGAN, 1991). No bojo deste processo, o Estado vai perdendo a capacidade de induzir e coordenar investimentos empresariais privados, cujo resultado levou a deterioração não só da infraestrutura tradicional como da infraestrutura em ciência e tecnologia (C\&T) (SARTI e HIRATUKA, 2011).

Nesse sentido, ao longo da década de 80 "as empresas reagiram reorientando as estratégias de crescimento para o mercado externo, reduzindo os níveis de endividamento, aumentando o mark up, realizando investimentos localizados (nos setores exportadores) e de tipo defensivo (racionalização e modernização da capacidade existente), em detrimento dos investimentos em expansão ou instalação de novas unidades de produção" (LAPLANE e SARTI, 2006, pg. 275). A década de 90 é marcada pelo aprofundamento de políticas neoliberais, onde a premissa da concorrência foi considerada elemento central para a promoção da rápida transformação da estrutura produtiva, por meio da modernização de plantas industriais em razão do barateamento dos bens de capital, e redução da verticalização, na direção de uma alocação de recursos mais afinada com as vantagens comparativas (CARNEIRO, 2002; CARNEIRO, 2008).

Todavia, segundo Carneiro (2002), o resultado foi a desnacionalização da economia nacional, alavancada pelo processo de privatização, em que empresas foram compradas para posteriormente serem vendidas, demonstrando nítido caráter especulativo. Do ponto de vista da firma, "as empresas reagiram à abertura e à política econômica aprofundando a especialização e a racionalização da capacidade produtiva, com forte redução de emprego. $\mathrm{O}$ ajuste foi realizado com baixo investimento, introdução de mudanças organizacionais e abandono de linhas de produtos. Além disso, constatou-se que as empresas nacionais procuraram parceiros estrangeiros para estabelecer acordos de complementação de linhas de produtos importados e de prestação de serviços no mercado doméstico" (LAPLANE e SARTI, 2006, pg. 275). Por fim, a taxa de investimento passou a apresentar dois fenômenos, sendo eles: 1) a desarticulação do ponto de vista dos macrossetores, indústria e infraestrutura, e; 2) uma redução do encadeamento intra-setorial em função do aumento da participação das máquinas e equipamentos importados (CARNEIRO, 2002).

Desse modo, o quadro geral para o Brasil em fins da década de 90 e início de 2000 foi a obsolescência da capacidade operacional, e de planejamento do sistema de infraestrutura em decorrência de longos anos de estagnação, com desemprego estrutural e desigualdades sociais, que levaram a contração do mercado, com baixos níveis de consumo per capita da grande maioria de produtos industriais. Além disso, todas as atividades e rotinas cujo aumento da competitividade não pudesse ser obtido de imediato, com a velocidade e a economia de investimentos que a economia brasileira em transformação exigia, foram abandonadas pelas empresas (CARNEIRO, 2008; LAPLANE e SARTI, 2006). Portanto, o perfil da produção industrial brasileira passou a sofrer modificações no sentido da especialização em atividades intensivas em recursos naturais, abandono da busca por inovações, e com menor exposição à concorrência externa levando a um processo chamado de "especialização regressiva" da produção industrial brasileira (COUTINHO, 1997; GONÇALVES, 2001; LAPLANE E SARTI, 2006; PRATES, 2006).

A partir de meados da década de 2000, esforços voltados para a elaboração e implementação de política industrial voltam a fazer parte da esfera de ação do Estado. Como aponta Coronel (2014), em 2004 é lançada a Política Industrial, Tecnológica e de Comércio Exterior (PITCE) visando fomentar o setor industrial, mas, que por falta de objetivos bem definidos e pela conjuntura econômica desfavorável, os resultados foram insatisfatórios. Em 2008, novo esforço é realizado por meio da Política de Desenvolvimento Produtivo (PDP), que segundo Cano e Silva (2010), ampliou o conjunto de instrumentos e de setores contemplados, ao mesmo tempo em que procurou aprofundar a capacidade de planejamento, coordenação e gestão da política. Todavia, não conseguiu atingir boa parte de suas metas devido a falta de critérios e objetivos para os setores considerados estratégicos (CORONEL, 2014). 
Por fim, em 2011, foi lançado o Plano Brasil Maior (PBM) que continha uma série de medidas dentre elas "o "plano piloto" da desoneração da folha, bem como a instituição de um "reintegro" sobre o valor das exportações a título de ressarcimento aos exportadores por tributos que não foram recuperados quando da venda de produtos para o exterior. Além disso, o governo completou a remoção de tributos federais sobre o investimento. Em suma, foram reduzidos os custos tributários" (ALMEIDA, 2011, pg. 11). Entretanto, como aponta Kupfer (2013), diante da continuidade dos efeitos da crise internacional de 2008, e do aumento da competitividade internacional, o plano passou a se concentrar mais na defesa do mercado doméstico do que em reformas estruturais, inviabilizando desta forma a possibilidade de adensamento produtivo. Adicionalmente, diante das debilidades institucionais tanto na dimensão técnico-administrativa como na dimensão política, o PBM caracterizou-se por ser um plano com caráter mais de viés corretivo ricardiano - do que um plano voltado para a inovação - schumpeteriano, em que, permeado por processos decisórios carentes de efetividade institucional padeceu de uma espécie de cacofonia decisória, evidenciando portanto um problema de coordenação intra-governamental (SHAPIRO, 2013).

\section{A dinâmica econômica do Brasil em relação ao mundo}

As taxas de crescimento do Produto Nacional nos últimos vinte e três anos, gráfico 01, evidencia duas diferenças básicas quanto ao comportamento da geração de riqueza. A Europa e os Estado Unidos que alcançaram a maturidade de seus parques produtivos, exibiram taxas de crescimento menores em relação aos países em desenvolvimento, e principalmente, em relação aos países asiáticos. Estes, mais especificamente a China e a Índia, apresentaram taxas de crescimento em média próximas de 7\% ou mais, com tendência a certa estabilidade do crescimento em patamares mais elevados. No caso da América do Sul e Central, ao longo das últimas décadas, observa-se a "vocação" às oscilações da taxa de crescimento de seu produto, como é o caso do Brasil, da Argentina, e o Chile, trazendo à baila a discussão sobre as formas passíveis de promoção do crescimento, e por extensão, o modo como os países se inserem no comércio internacional.

\section{Gráfico 1: Taxa de crescimento médio anual do Produto Nacional de países selecionados, 1992 - 2015 (\%).}

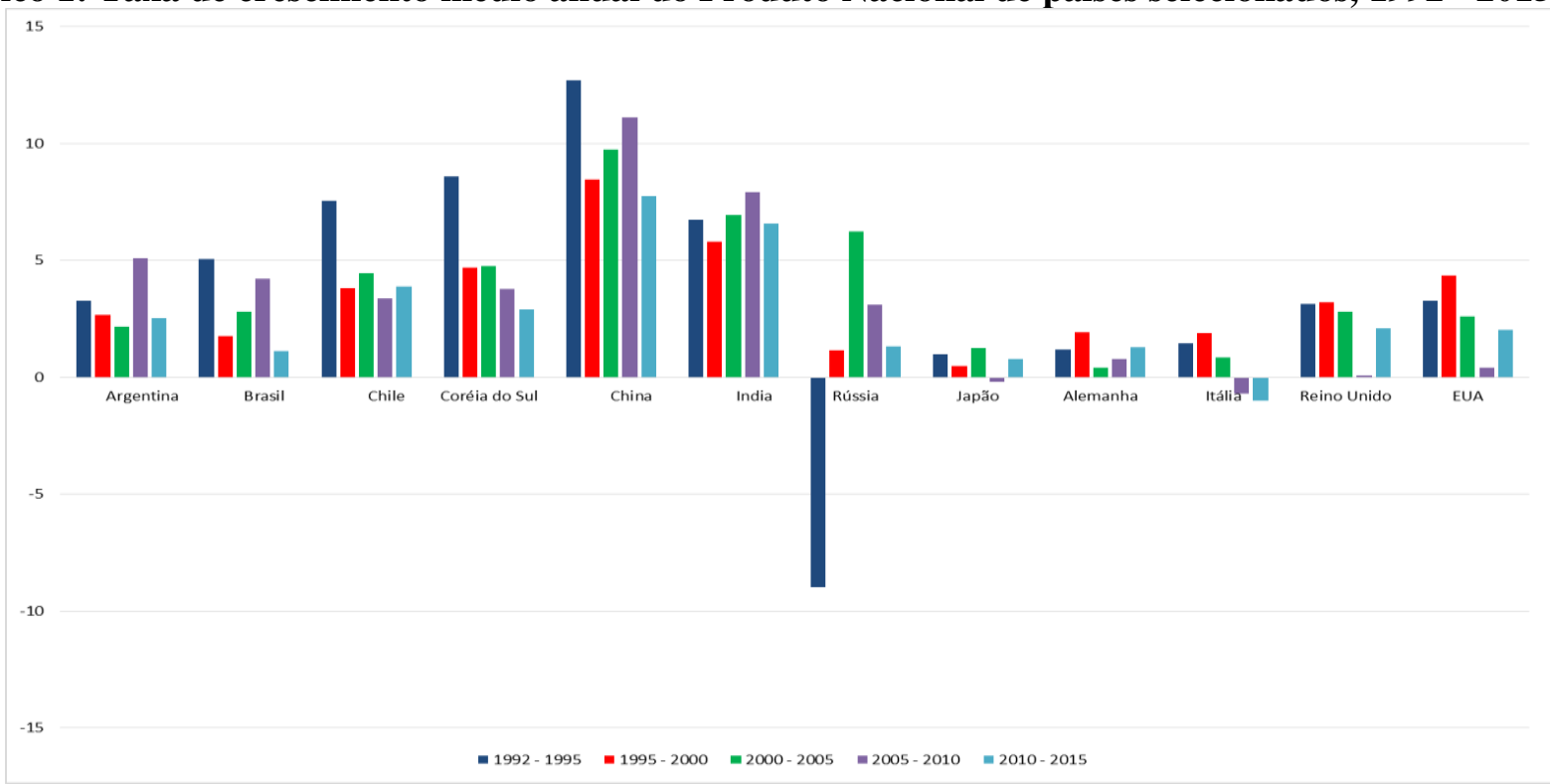

Fonte: Elaboração a partir dos dados da UNCTADSTAT.

Se a década de 70 foi considerada o período áureo do crescimento econômico brasileiro, período este marcado por forte intervenção estatal por meio dos Planos Nacionais de Desenvolvimento que levaram a economia brasileira a crescer anualmente em média valores próximos de $10 \%$, as décadas atuais, tem sido caracterizadas não só pelas fortes oscilações no crescimento econômico, mas também pelo fenômeno da desindustrialização. A literatura sobre o tema tem apontado que o processo de desindustrialização vem ocorrendo no mundo desenvolvido desde a década de 70. Autores como Rowthorn e Ramaswany (1999); Rowthorn e Ramaswany (1999); Rowthorn e Ramaswany (2004); Palma (2005) e Tregenna (2009) colocam 
que esse processo é resultado do aumento da produtividade da indústria, cujo consequência foi a perda de participação desta no PIB, e no emprego total dos países avançados. Todavia, no caso dos países em desenvolvimento, o processo de desindustrialização adquiri um caráter precoce ou nocivo, na medida em que, antes de atingirem um nível de renda per capita compatível com os países desenvolvidos, o processo de desindutrialização tem levado a perda de participação da indústria de tranformação no PIB, e o deslocamento de parcela da força de trabalho para atividades menos intensivas em conhecimento no setor de serviços (PEREIRA, 2016).

Desta feita, o caso brasileiro tem sido caracterizado como o de uma desindustrialização precoce, em que o país vem se destacando negativamente nesse processo, tanto em intensidade dentro da América Latina, quanto no sentido da posição relativa em relação aos países em desenvolvimento. O gráfico 02 mostra a Desindustrialização Relativa Internacional - DRI do Brasil, e de um conjunto de regiões e grupos de países selecionados, de modo que o eixo vertical à esquerda corresponde às economias que evoluíram para uma DRI menor que 1, ou seja, países que se desindustrializaram em relação ao mundo, e o eixo vertical à direita, corresponde às economias que tiveram uma DRI maior que 1, e que portanto, se industrializaram em relação ao mundo (AREND, 2014). Nesse sentido, constata-se que o Brasil segue trajetória inversa a das economias em desenvolvimento e dos novos países industrializados - NICs, pois apresentou em 2015 um DRI correspondente a 56\% do desempenho da indústria mundial.

Constata-se portanto, uma DRI maior que o da África em desenvolvimento que correspondeu a 96\%, bem como das economias desenvolvidas que apresentaram um DRI de 69\%, e das Américas do Sul e Central que atingiram 69\% no índice DRI. Por outro lado, países como a China, e os integrantes dos NICs de primeira geração (Taiwan, Singapura, Coreia do Sul e Hong Kong), e NICs de segunda geração (Indonésia, Malásia e Tailândia) apresentaram trajetórias continuamente positivas. No caso da Ásia, destaca-se a China que vem apresentando desde a década de 90, valores progressivamente elevados, atingindo em 2015 índice de industrialização 13\% superior ao desempennho médio mundial. Os NICs de primeira e segunda gerações apresentaram desempenho superior ao mundial em $4 \%$, e $2,1 \%$ respectivamente, evidenciando trajetória positiva e sustentada por parte da indústria destes países asiáticos, e cujo efeito em termos produtivos e de inovação tendem a ser mais sustentáveis ao longo do tempo.

Gráfico 2: Índice de desindustrialização relativa internacional, DRI 1980 - 2014.

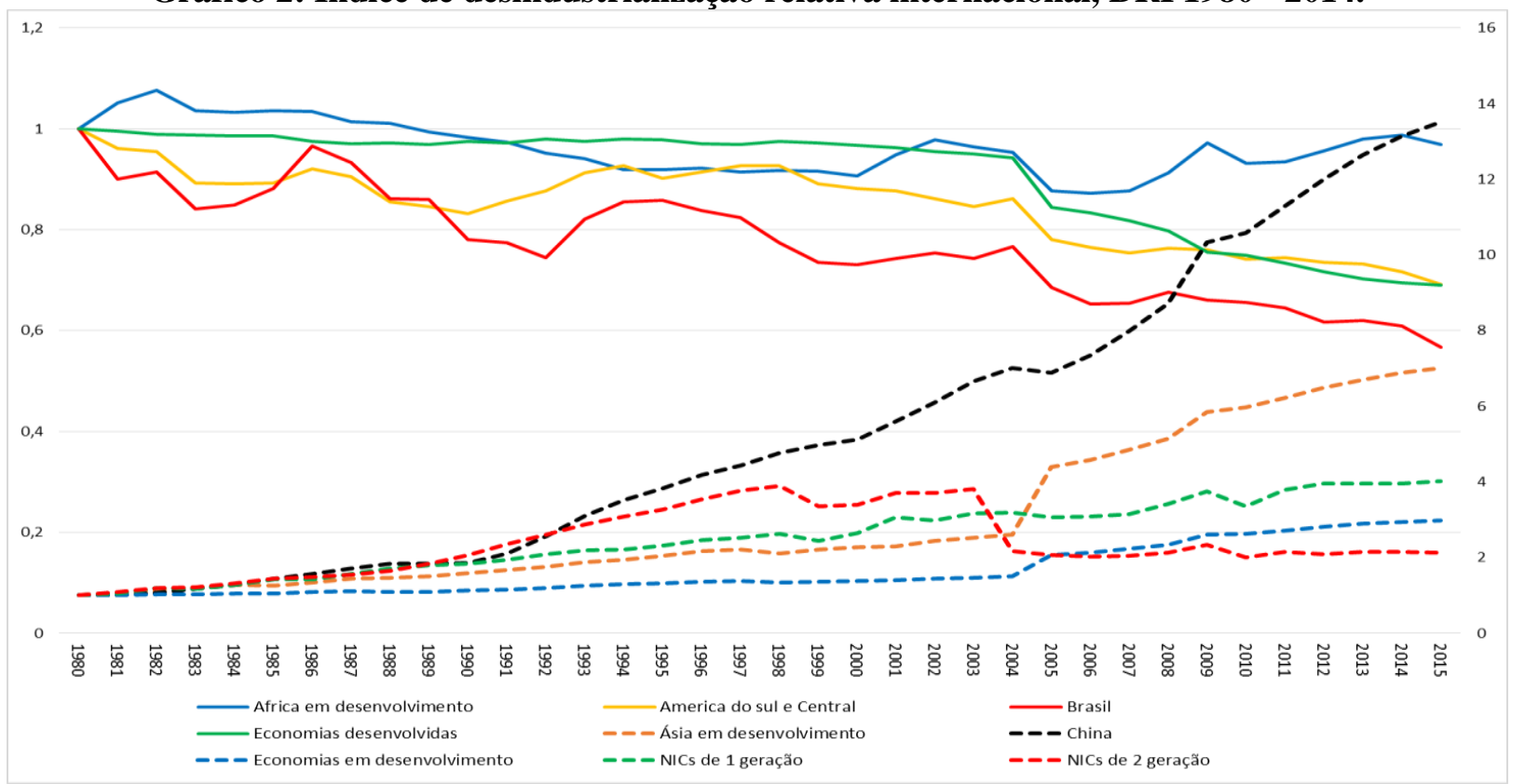

Fonte: UNCTADSTAT a partir de metodologia de Arend (2014). DRIs construídos a partir do IVI em US\$ constantes de 2005 .

Nestas circunstâncias, observa-se duas características quanto ao comportamento da indústria de transformação mundial, a saber: a) a primeira marcada pela desindustrialização natural, compreendendo os paises desenvolvidos com parque industrial maduro por um lado, e por outro, a desindustrialização precoce, 
onde incluem-se os países marcados por estrutura industrial heterogênea e incompleta, com presença de recursos naturais abundantes, como é o caso dos países latino americanos, especialmente o Brasil, e; b) a segunda característica, onde se enquadram os países asiáticos, cuja dinâmica de industrialização tem apresentado trajetória positiva ao longo de décadas como é o caso dos NICs de primeira e segunda geração.

Como o Brasil se enquadra na condição de um país em processo de desindustrialização precoce, o resultado não só é a ampliação do gap em relação aos países asiáticos, no que tange às taxas de crescimento, quanto na capacidade de geração e absorção de progresso técnico e inovativo. Essa tendência pode ser observada pelo gráfico 3 A e B, que apresenta a solicitação de registro de patentes como proxy para o ritmo de inovação entre os países. Em termos absolutos, gráfico 3 A, China, Estados Unidos, Japão e Coréia do Sul lideram o registro de patentes, cabendo destacar que durante os 20 anos analisados apenas o Japão apresentou redução na capacidade inovativa, ao passo que todos os demais países em destaque apresentaram crescimento progressivo. Em termos per capita, Córeia do Sul, Japão, Estados Unidos e China respectivamente, mantiveram sua capacidade inovativa ao longo do tempo, apesar da perda de ritmo por parte do Japão. No caso do Brasil, apesar de tanto em termos absolutos (gráfico A), quanto per capita (gráfico B) o comportamento indicar uma evolução positiva e mais significativa que os demais vizinhos, o processo de inovaçao ainda é tímido em relação aos países desenvolvidos e em desenvolvimento. Mais especificamente, se compararmos com a Rússia e Índia, países que como o Brasil compõem o BRICS, o país apresenta um desempenho modesto no quadro dos países em desenvolvimento.

Gráfico 3: Solicitaçao de registro de patentes total, (A) e per capita (B) para paises selecionados, 1995 a 2015.

A

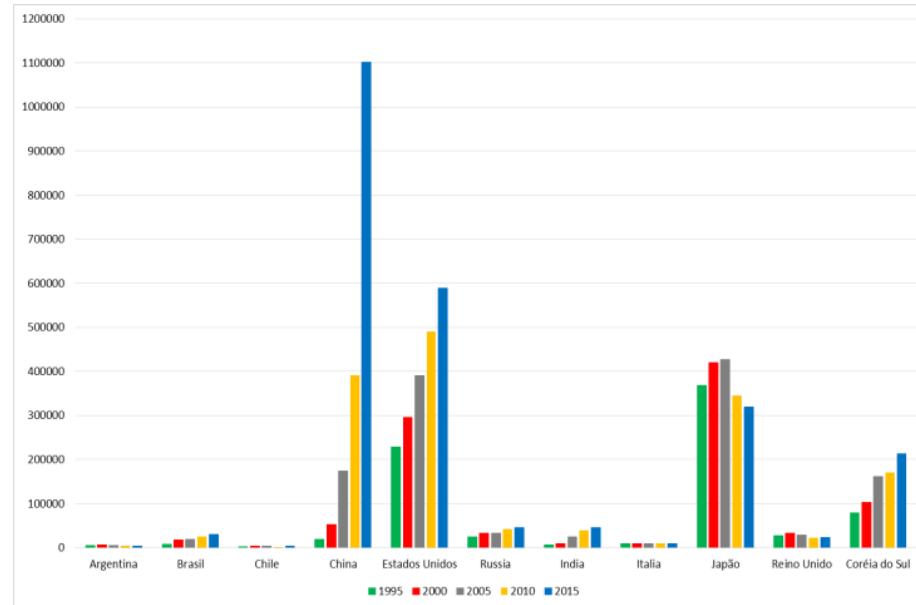

B

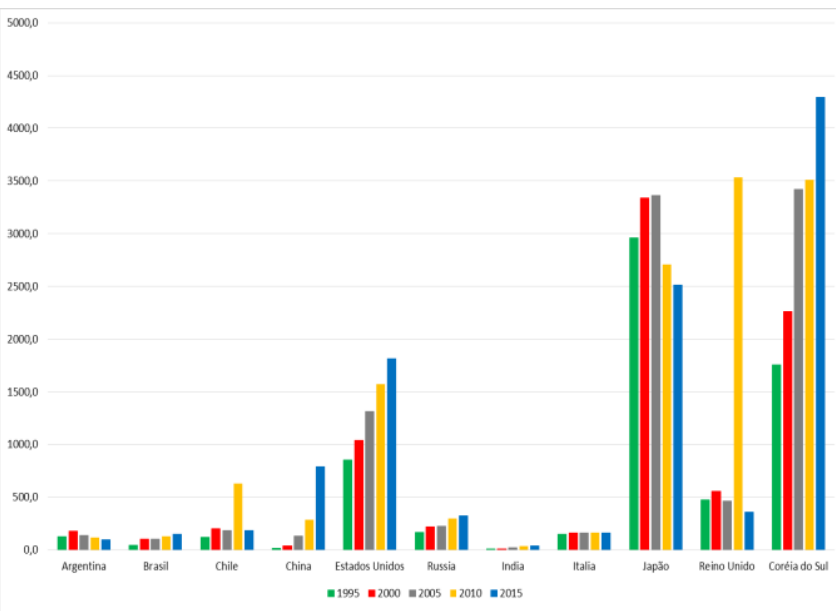

Fonte: Elaborado a partir da OMPI e World Bank.

Assim, contextualizada a situação brasileira do ponto de vista internacional, cabe avaliar as principais variáveis macroeconômicas que contribuem para o desempenho econômico entre os países a saber: o câmbio e a taxa de juros real. Isso se deve pelo fato de que estas variáveis afetam não só a dinâmica econômica interna ao viabilizar o investimento, mas também afetam a competitividade internacional dos países no que tange ao comércio internacional. Deste modo, ao se analisar o gráfico 4 A, observa-se que, entre 1994 e 2015, países como Coréia do Sul e Índia não só já apresentavam taxas cambiais mais desvalorizadas, como em conjunto com a Rússia apresentaram trajetória de maior desvalorização cambial em comparação aos demais paises selecionados. Considerando que o Brasil adotou o câmbio como âncora para a estabilização dos preços a partir de 1994, observa-se que aquele apresentou as menores taxas de desvalorização ao longo dos vinte e um anos em análise. Nestas condições, as importações tenderam a ser mais estimuladas que as exportações, via de regra como estratégia macroeconômica para conter o processo inflacionário, ao passo que as exportações brasileiras, concentraram-se em commodities. 
Gráfico 4: Evolução das Taxas de câmbio (A) e de juros real (\%) (B), 1994/1996 a 2015.

A

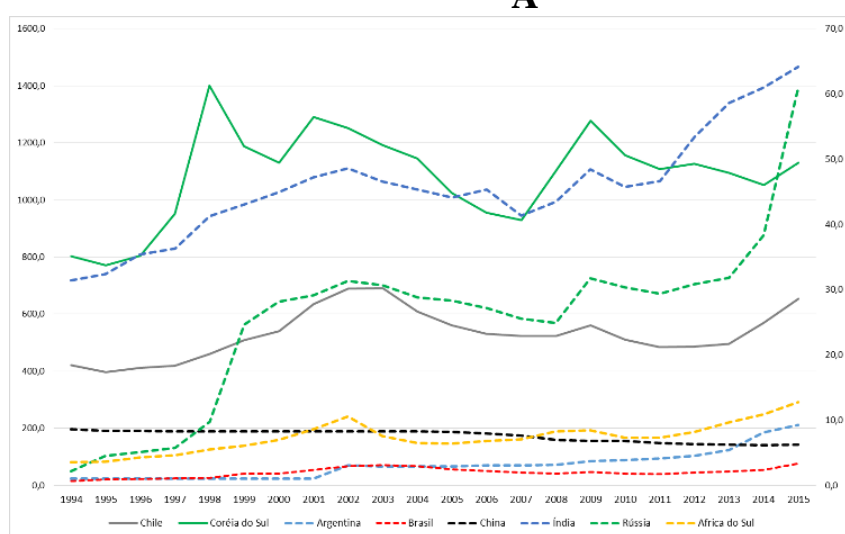

B

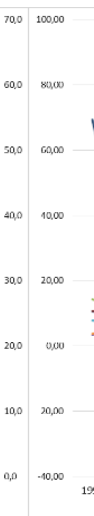

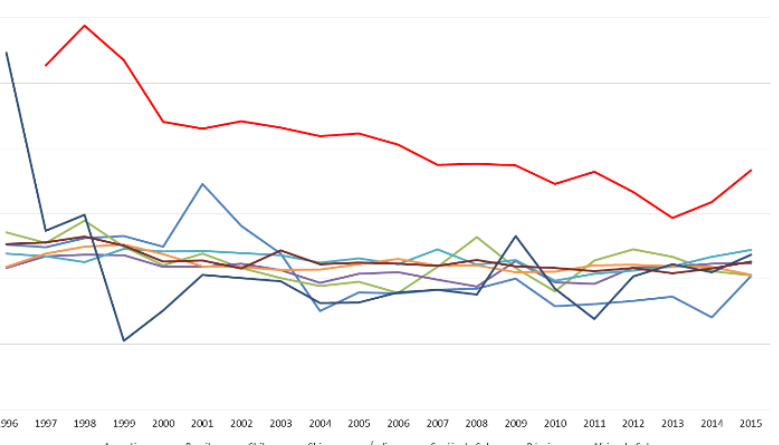

Fonte: FMI

Do ponto de vista do juro real (gráfico 4 B), o Brasil foi o país que apresentou ao longo de todo o período, as maiores taxas de juro real entre os países selecionados. Apesar da trajetória de queda mais consistente a partir do ano 2000, e mais intensificada a partir do ano de 2011, como um esforço voltado para estimular a economia brasileira no período pós crise internacional, a partir de 2013 a trajetória se reverte como resultado da ação do Banco Central do Brasil em conter a escalada inflacionária. Em outros termos, ao longo de dezenove anos, a economia brasileira conviveu com uma das taxas de juro real mais elevadas, e que comparativamente em relação aos demais países em desenvolvimento, influencia na tomada de decisão de investimento tanto internamente quanto internacionalmente.

Assim, no que tange à dimensão internacional depreende-se que o Brasil caracterizou-se por ser um país caracterizado por taxas de crescimento instável do Produto Nacional ao longo das últimas décadas, e marcado por um processo de desindustrialização em curso, cuja tendência mostrou-se mais intensa a partir de meados da década de 90. Concomitantemente, o processo de inovação brasileiro, muito embora tenha apresentado evolução positiva, foi modesto quando comparado com os demais países em desenvolvimento. Em outros termos, o Brasil vem perdendo competitividade internacional em um quadro caracterizado pela perda de importância da indústria, e com baixa taxa de inovação, onde variáveis macroeconômicas (câmbio e juros) que expressam uma dimensão da política implícita são responsáveis por parcela importante desse resultado.

\section{A política implíta brasileira: evidências empíricas}

O gráfico 05 apresenta a evolução da participação da indústria de transformação no PIB e o grau de abertura da economia. Observa-se que de 1953 a 1984, fase esta caracterizada pelo período de menor abertura da economia brasileira, a indústria de transformação alcançou participações continuamente elevadas na formação do PIB. Importante notar que esse comportamento reflete um conjunto de políticas voltadas para o desenvolvimento econômico originadas da CEPAL, com vistas à proteção da indústria infante, e os estímulos à economia foram recorrentes na década de 70. Todavia, a partir de 1985, observase um processo de perda de participação da indústria de transformação, concomitantemente ao inicio de uma trajetória de ampliação do grau de abertura econômica. Para além disso, do ponto de vista macroeconômico, esse comportamento coincide com o momento de crise fiscal do Estado e da necessidade do país em reverter déficits recorrentes na balança comercial em um processo de ajuste estrutural da economia. 


\section{Gráfico 5: Participação do PIB da Indústria de transformação no PIB Nacional e Grau de Abertura da} Economia 1950-2014 - (\%).

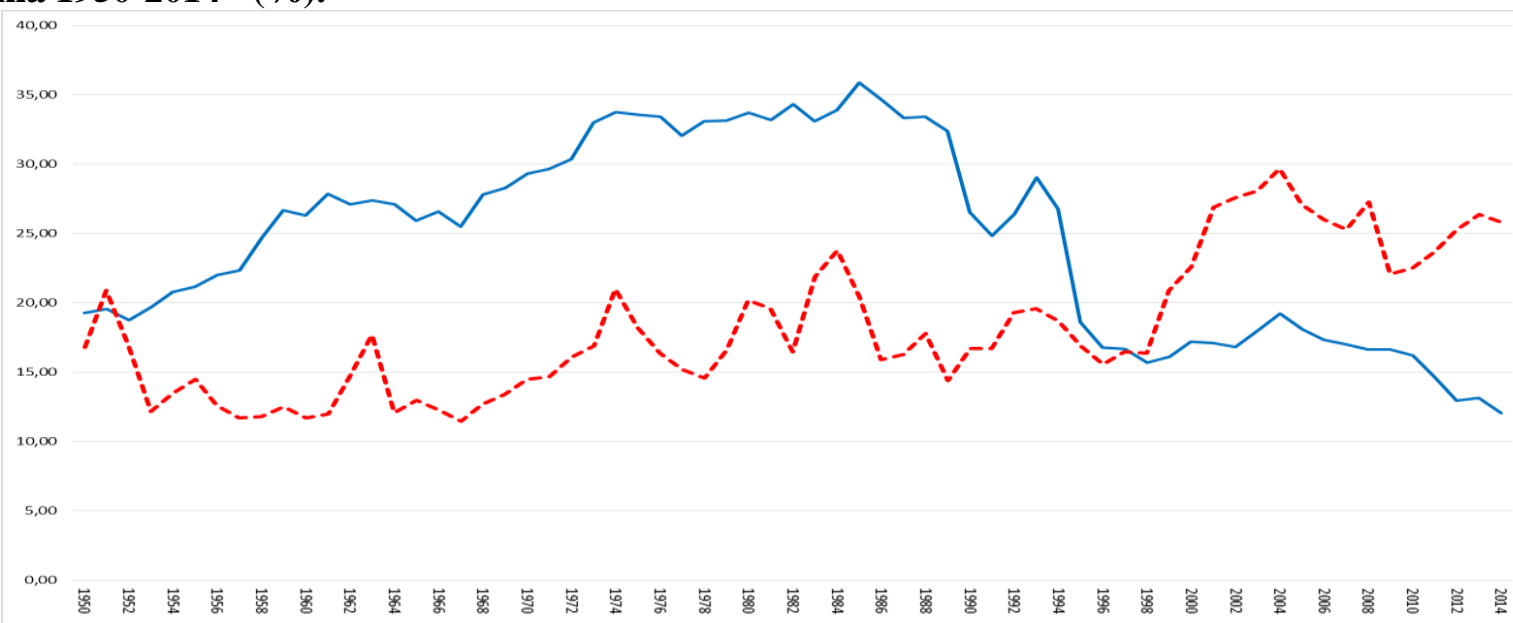

\section{Fonte: IPEADADATA}

O período de ampla abertura econômica da segunda metade da década de 90, foi resultado de uma orientação mais liberalizante da economia conhecida como neo-liberalismo, cujas diretrizes básicas podem ser encontradas no Consenso de Washington ${ }^{\ddagger}$. Neste período, observa-se pequeno aumento da participação da indústria, cuja reversão de tal trajetória ocorreu a partir de meados da década dos anos 2000 , já em um contexto de revisão das propostas de cunho liberal. No esteio desse processo, partir de 2004 o grau de abertura da economia voltou a se reduzir, entrentanto a perda de participação da indústria no PIB continuou a avançar sistematicamente até antingir em 2014, cerca de $12 \%$ na formação da riqueza nacional. Em outros termos, esse comportamento sugere que existem outros fatores que influenciaram a queda de participação da indústria brasileira no PIB que vão além da exposição da indústria nacional ao mercado internacional.

Para tanto, se considerarmos a presença do Estado como agente indutor de desenvolvimento, através de seus gastos em P\&D\&I, podemos ampliar o campo de análise da política implicíta para além da política monetária, conforme apontado por Sagasti (1978) ao colocar que os dispêndios fiscais correspondem a uma dimensão da política implícita de C\&T\&I. A tabela 01 corresponde ao dispêndio dos governos federal e estaduais, aqui considerando os empenhos liquidados dos recursos do Tesouro, e de outras fontes do orçamento fiscal, visando avaliar o esforço do setor público em estimular a ciência e a tecnologia nacional. Por se tratar de variável discricionária, está sugeita às orientações macroeconômicas relativas ao ajuste ou expansão fiscal, a partir da concepção acerca do papel do Estado no processo de desenvolvimento econômico. Deste modo, considerando o dispêndio público em relação ao total gasto em C\&T, constata-se que de 2000 até 2005 ocorreu redução continuada, quando a partir de então, iniciou-se reversão da trajetória da participação do setor público no total do gasto em C\&T até atingir no ano de 2014 cerca de 52,06\%.

Todavia, a partir de 2005 os dispêndios empresariais começaram a apresentar redução gradativa até o ano de 2013, mas com pequena reverção em 2014 ao atingir 47,94\%. Em outros termos, as trajetórias de participação do dispêndio público, refletem em parte, a orientação de política econômica vigente entre 1994 e 2004, onde o Estado passou a ser menos ativo na condução da economia, ao passo que a partir de 2005 a diretriz de política econômica alterou-se completamente ${ }^{\S}$, cujo resultado foi uma variação do dispêndio público em cerca de 4 p.p.. Ponto relevante é que a participação do dispêndio público em C\&T ao longo do período analisado sempre foi superior aos dispêndios empresariais, apesar de neste setor institucional conter empresas estatais como a Petrobrás cujos investimentos em $\mathrm{P} \& \mathrm{D}$ responde por grande parte dos investimentos empresariais.

Comportamento idêntico se observa ao analisar as instituições de ensino públicas federais, que após cinco anos marcados por trajetória de queda no percentual do dispêndio em C\&T, passaram a apresentar a partir de 2006, reversão dos dispêndios em C\&T. Entretanto, cabe ressaltar que salvo algumas oscilações

\footnotetext{
${ }^{\ddagger}$ Para mais detalhes acesse: $\underline{\text { https://piie.com/publications/papers/williamson0904-2.pdf }}$

$\S$ Para mais detalhes: (BARBOSA FILHO, 2015).
} 
entre 2008 e 2009, a retomada do rítmo do dispêndio a partir de 2005 foi suficiente para fazer com que o nível do gasto se equiparasse aos valores do início da série. Em outros termos, a retomada do gasto em P\&D a partir de 2005, ao atingir uma variação de aproximadamente 2,7 p.p. até 2014 conseguiu praticamente equiparar-se aos percentuais gastos no ano de 2000.

Tabela 01: Dispêndio nacional em ciência e tecnologia $(C \& T)$, em relação ao total de C\&T e ao produto interno bruto (PIB), por setor institucional, 2000-2014.

\begin{tabular}{|c|c|c|c|c|c|c|c|c|c|c|c|c|c|c|c|c|c|c|c|c|c|c|c|c|c|c|c|c|c|c|}
\hline \multirow{2}{*}{ Setores } & \multicolumn{15}{|c|}{ \%em relação ao total de C\&T } & \multicolumn{15}{|c|}{ \%em relação ao PIB } \\
\hline & 2000 & 2001 & 2002 & 2003 & 2004 & 2005 & 2006 & 2007 & 2008 & 2009 & 2010 & 2011 & 2012 & 2013 & $2014^{(7)}$ & 2000 & 2001 & 2002 & 2003 & 2004 & 2005 & \begin{tabular}{|l|l|}
2006 \\
\end{tabular} & \begin{tabular}{|l|r|}
2007 & \\
\end{tabular} & 2008 & \begin{tabular}{|l|l|l|l|l|l|l|}
2009 \\
\end{tabular} & 2010 & \begin{tabular}{|l|l|}
2011 \\
\end{tabular} & 2012 & 2013 & $2014^{(7)}$ \\
\hline $\begin{array}{c}\text { Total } \\
\end{array}$ & 100,00 & 100,00 & 100,00 & 100,00 & 100,00 & 100,00 & 100,00 & 100,00 & 100,00 & 100,00 & 100,00 & 100,00 & 100,00 & 100,00 & 100,00 & 1,32 & 1,34 & 1,33 & 1,30 & 1,30 & 1,30 & 1,27 & 1,38 & 1,46 & 1,54 & 1,60 & 1,56 & 1,59 & 1,61 & 1,66 \\
\hline Dispêndios públicos & 54,61 & 54,11 & 50,59 & 49,82 & 49,49 & 48,25 & 51,60 & 52,77 & 50,89 & 52,34 & 52,68 & 51,82 & 52,37 & 55,93 & 52,06 & 0,72 & 0,73 & 0,67 & 0,65 & 0,64 & 0,63 & 0,65 & 0,73 & 0,74 & 0,81 & 0,84 & 0,81 & 0,83 & 0,90 & \\
\hline Dispêndios federais' & 36,59 & 35,49 & 33,01 & 33,18 & 34,15 & 33,96 & 37,58 & 37,59 & 35,17 & 35,95 & 36,28 & 34,41 & 34,52 & 38,41 & 34,74 & 0,48 & 0,48 & 0,44 & 0,43 & 0,44 & 0,44 & 0,48 & 0,52 & 0,51 & 0,55 & 0,58 & 0,54 & 0,55 & 0,62 & \\
\hline çamento execu & 26,97 & 26,48 & 23,59 & 23,49 & 24,16 & 24,68 & 26,71 & 25,87 & 24,09 & ;12 & 26,53 & 23,96 & 24,05 & 27,06 & 23,11 & 0,36 & 0,36 & 0,31 & 0,30 & 0,31 & 0,32 & 0,34 & 0,36 & 0,35 & 0,40 & 0,42 & 0,37 & 0,38 & 0,43 & 0,3 \\
\hline ós-graduaçāo & 9,62 & 9,01 & 9,42 & 9,69 & 10,00 & 9,28 & 10,87 & 11,72 & 11,08 & 83 & 9,75 & 10,46 & 10,47 & 11,35 & 11,63 & 13 & 0,12 & 0,13 & 0,13 & 0,13 & 0,12 & 0,14 & 0,16 & 16 & 0,15 & 0,16 & 0,16 & 0,17 &, 18 & \\
\hline ispêndios estaduais ${ }^{1 / 2}$ & 18,02 & 18,62 & 17,58 & 16,63 & 15,33 & 14,29 & 14,02 & 15,18 & 15,72 & 16,39 & 16,40 & 17,41 & 17,85 & 17,52 & 17,32 & 0,24 & 0,25 & 0,23 & 0,22 & 0,20 & 0,19 & 0,18 & 0,21 & 0,23 & 0,25 & 0,26 & 0,27 & 0,28 & 0,28 & \\
\hline rçamento executado & 8,27 & 8,66 & 7,60 & 7,21 & 8,06 & 7,32 & 7,47 & 7,11 & 7,79 & 9,16 & 9,15 & 8,86 & 9,20 & 8,61 & 7,72 & 0,11 & 0,12 & 0,10 & 0,09 & 0,10 & 0,10 & 0,09 & 0,10 & 0,11 & 0,14 & 0,15 & 0,14 & 0,15 &, 14 & \\
\hline Pós-graduaçāo & 9,75 & 9,96 & 9,98 & 9,42 & 7,27 & 6,97 & 6,55 & 8,07 & 7,93 & 7,23 & 7,24 & 8,55 & 8,65 & 8,91 & 9,60 & 0,13 & 0,13 & 0,13 & 0,12 & 0,09 & 0,09 & 0,08 & 0,11 & 0,12 & 0,11 & 0,12 & 0,13 & 0,14 & 0,14 & 0,1 \\
\hline Dispêndios empresariais & 45,39 & 45,89 & 49,41 & 50,18 & 50,51 & 51,75 & 48,40 & 47,23 & 49,11 & 47,66 & 47,32 & 48,18 & 47,63 & 44,07 & 47,94 & 0,60 & 0,62 & 0,66 & 0,65 & 0,66 & 0,67 & 0,61 & 0,65 & 0,72 & 0,74 & 0,76 & 0,75 & 0,76 & 0,71 & 0,8 \\
\hline Outras en & 7,09 & 8,93 & 12,60 & 12,74 & 13,06 & 11,34 & 9,45 & 9,25 & 10,74 & 13,06 & 11,91 & 13,73 & 15,65 & 12,59 & 11,79 & 0,09 & 0,12 & 0,17 & 0,17 & 0,17 & 0,15 & 0,12 & 0,13 & 0,16 & 0,20 & 0,19 & 21 & 0,25 &, 20 & 0,2 \\
\hline ós-graduaçāo(6) & 0,91 & 1,02 & 1,22 & 1,44 & 1,41 & 1,47 & 1,53 & 1,79 & 1,64 & 1,57 & 1,34 & 1,37 & 1,42 & 1,45 & 1,70 & 0,01 & 0,01 & 0,02 & 0,02 & 0,02 & 0,02 & 0,02 & 0,02 & 0,02 & 0,02 & 0,02 & 0,02 & 0,02 & 0,02 & \\
\hline
\end{tabular}

\section{Fontes: PINTEC/IBGE-SERPRO}

No que tange ao gasto percentual em relação ao PIB, podemos constatar que ao longo de quatorze anos a evoluçao do gasto foi relativamente tímida, tanto por parte do setor público, quanto por parte do sertor empresarial, cujos dispêndios não ultrapassaram 1\% do PIB. Similarmente, podemos constatar duas trajetórias, sendo que do ano de 2000 até o ano de 2005 o gasto foi marcado por uma trajetória suave de queda, sugerindo que durante esse período o esforço científico e tecnológico por parte do setor público foi restrito. Todavia, entre 2006 e 2014 observa-se um crescimento de aproximadamente 0,5 p.p. que embora represente um crescimento modesto, sinaliza a existência de um esforço público voltado ao estímulo da inovação. Os gastos empresariais, salvo algumas oscilações, apresentaram trajetória crescente, muito embora sua participação a partir de 2006 tenha se mantido sempre abaixo da participação do setor público. Em outros termos, o setor empresarial ainda mantêm-se reticente quanto ao gasto relacionado à ciência e tecnologia, mesmo diante dos esforços por parte dos policy makers no sentido de garantir estabilidade macroeconômica e viabilizar incentivos fiscais e creditícios. O governo federal se destacou nesse movimento de liderança do gasto em função do PIB, mesmo após a crise financeira internacional de 2008/2009 cuja retração não foi maior devido à manutenção dos gastos em âmbito federal.

Ao se analisar especificamente as atividades de P\&D (tabela 02) cujo resultado para a inovação é mais significativo, constata-se que o dispêndio público a partir de 2005 apresentou trajetória de crescimento progressivo até o ano de 2013, atingindo 57,70\%, ou seja, crescimento de 10 p.p ressaltando-se que em 2014 registrou-se indicativo de queda. Importante destacar que, por outro lado, os dispêndios empresariais apresentaram trajetória de queda no mesmo ano em que o gasto público total e federal começou a aumentar progressivamente, sendo a retração mais intensa a partir de 2010, com queda de 1,5 p.p. até 2014. Esse comportamento requer uma análise mais criteriosa, uma vez que essa trajetória de queda poderia ser muito maior caso a categoria dispêndios empresariais não incluíssem empresas estatais. Sob qualquer aspecto, os dados demonstram que o esforço inovativo concentra-se mais intensamente nas instituições de ensino e pesquisa, e que este comportamento foi mais significativo a partir dos anos de 2006, quando reverte-se a trajetória de queda dos gasto que já vinham ocorrendo desde o ano 2000.

Tabela 02: Dispêndio nacional em pesquisa e desenvolvimento (P\&D) por setores, em relação ao total de P\&D e ao produto interno bruto (PIB), 2000-2014.

\begin{tabular}{|c|c|c|c|c|c|c|c|c|c|c|c|c|c|c|c|c|c|c|c|c|c|c|c|c|c|c|c|c|c|c|}
\hline \multirow{2}{*}{ Setores } & \multicolumn{15}{|c|}{ \%em relação ao total de P\&D } & \multicolumn{15}{|c|}{ \%em relação ao PIB } \\
\hline & 2000 & 2001 & 2002 & \begin{tabular}{|l|l|}
2003 \\
\end{tabular} & 2004 & 2005 & 2006 & 2007 & 2008 & \begin{tabular}{|l|l|l|}
2009 & 2 \\
\end{tabular} & 2010 & \begin{tabular}{|l|l|l|}
2011 & 2 \\
\end{tabular} & 2012 & \begin{tabular}{|l|l|}
2013 & 2 \\
\end{tabular} & $2014^{(5)}$ & 2000 & 2001 & 2002 & \begin{tabular}{|l|l|l|}
2003 & -1 \\
\end{tabular} & 2004 & 2005 & 2006 & 2007 & 2008 & 2009 & 2010 & 2011 & 2012 & 2013 & $2014^{(5)}$ \\
\hline Total & 100,00 & 100,00 & 100,00 & 100,00 & 100,00 & 100,00 & 100,001 & 100,00 & 100,00 & 100,001 & 100,00 & 100,001 & 100,00 & 100,001 & 100,00 & 1,05 & 1,06 & 1,01 & 1,00 & 0,96 & 1,00 & 0,99 & 1,08 & 1,13 & 1,12 & 1,16 & 1,14 & 1,13 & 1,20 & 1,27 \\
\hline Dispêndios públicos & 51,70 & 53,30 & 51,63 & 51,41 & 49,49 & 47,66 & 50,03 & 51,62 & 50,36 & 52,29 & 51,12 & 52,90 & 54,93 & 57,70 & 52,67 & 0,54 & 0,57 & 0,52 & 0,51 & 0,48 & 0,48 & 0,49 & 0,56 & 0,57 & 0,58 & 0,59 & 0,60 & 0,62 & 0,69 & 0,67 \\
\hline Dispêndios federais ${ }^{(1)}$ & 31,91 & 32,66 & 32,12 & 33,80 & 34,03 & 32,56 & 35,63 & 35,51 & 34,37 & 36,11 & 35,59 & 35,66 & 36,90 & 40,48 & 35,63 & 0,33 & $3 \quad 0,35$ & 0,32 & 0,34 & 0,33 & 0,33 & 0,35 & 0,38 & 0,39 & 0,40 & 0,41 & 0,41 & 0,42 & 0,48 & 0,45 \\
\hline Orçamento executado & 19,78 & 21,28 & 19,74 & 21,22 & 20,55 & 20,54 & 21,69 & 20,58 & 20,04 & 22,56 & 22,12 & 21,36 & 22,14 & 25,23 & 20,39 & 0,21 & 0,23 & 0,20 & 0,21 & 0,20 & 0,21 & 0,21 & 0,22 & 0,23 & 0,25 & 0,26 & 0,24 & 0,25 & 0,30 & 0,26 \\
\hline Pós-graduação & 12,13 & 11,38 & 12,38 & 12,58 & 13,48 & 12,02 & 13,94 & 14,93 & 14,34 & 13,55 & 13,47 & 14,30 & 14,76 & 15,25 & 15,23 & 0,13 & $3 \quad 0,12$ & 0,13 & 0,13 & 0,13 & 0,12 & 0,14 & 0,16 & 0,16 & 0,15 & 0,16 & 0,16 & 0,17 & 0,18 & $\begin{array}{ll}B & 0,19\end{array}$ \\
\hline Dispêndios estaduais s $^{(2)}$ & 19,79 & 20,64 & 19,51 & 17,61 & 15,47 & 15,10 & 14,40 & 16,11 & 15,98 & 16,19 & 15,53 & 17,24 & 18,03 & 17,23 & 17,04 & 0,21 & 0,22 & 0,20 & 0,18 & 0,15 & 0,15 & 0,14 & 0,17 & 0,18 & 0,18 & 0,18 & 0,20 & 0,20 & 0,21 & 0,22 \\
\hline rçamento executado & 7,50 & 8,05 & 6,40 & 5,39 & 5,66 & 6,07 & 5,99 & 5,84 & 5,73 & 6,23 & 5,53 & 5,55 & 5,83 & 5,25 & 4,47 & 0,08 & $3 \quad 0,09$ & 0,06 & 0,05 & 0,05 & 0,06 & 0,06 & 0,06 & 0,06 & 0,07 & ,06 & 0,06 & 0,07 & 0,06 & 0,06 \\
\hline Pós-graduaçāo & 12,30 & 12,59 & 13,11 & 12,22 & 9,81 & 9,03 & 8,41 & 10,28 & 10,25 & 9,96 & 10,00 & 11,69 & 12,20 & 11,98 & 12,57 & 0,13 & 0,13 & 0,13 & 0,12 & 0,09 & 0,09 & 0,08 & 0,11 & 0,12 & 0,11 & 0,12 & 0,13 & 0,14 & 0,14 & 0,16 \\
\hline Dispêndios empresariais & 48,30 & 46,70 & 48,37 & 48,59 & 50,51 & 52,34 & 49,97 & 48,38 & 49,64 & 47,71 & 48,88 & 47,10 & 45,07 & 42,30 & 47,33 & 0,51 & 0,50 & 0,49 & 0,49 & 0,49 & 0,52 & 0,49 & 0,52 & 0,56 & 0,53 & 0,57 & 0,54 & 0,51 & 0,51 & 0,60 \\
\hline 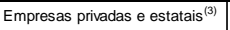 & 47,16 & 45,42 & 46,76 & 46,72 & 48,60 & 50,44 & 48,00 & 46,10 & 47,52 & 45,54 & 47,04 & 45,23 & 43,07 & 40,35 & 45,10 & 0,49 & 0,48 & 0,47 & 0,47 & 0,47 & 0,51 & 0,47 & 0,50 & 0,54 & 0,51 & 0,55 & 0,52 & 0,49 & 0,48 & 0,57 \\
\hline s-graduaçāa/4 & 1,14 & 1,28 & 1,61 & 1,87 & 1,91 & 1,90 & 1,96 & 2,28 & 2,13 & 2,16 & 1,85 & 1,87 & 2,00 & 1,95 & 2,23 & 0,01 & 0,01 & 0,02 & 0,02 & 0,02 & 0,02 & 0,02 & 0,02 & 0,02 & 0,02 & 0,02 & 0,02 & 0,02 & 0,02 & 0,03 \\
\hline
\end{tabular}

Fontes: PINTEC/IBGE-SERPRO 
Outra medida fiscal que se enquadra na conceito de política implícita corresponde à renúncia fiscal do governo federal para setores ligados à C\&T. A tabela 03 mostra a evolução destas renúncias para o período de 1994 a 2015, levando em consideração as seguintes leis, a saber: 1) Lei 8.010/90 que dispõe sobre importações de bens destinados à pesquisa científica e tecnológica; 2) Lei 8.032/90 que dispõe sobre a isenção ou redução de impostos de importação; 3) As Leis 8.248/91 e 10.176/01, que em conjunto são conhecidas por "Lei da informática", e que dispõem respectivamente sobre a capacitação e competitividade do setor de informática e automação, e que na nova versão dispõe sobre a capacitação e competitividade do setor de tecnologia da informação. Segundo Rapini (2010) na primeira versão da Lei da informática as empresas deveriam investir 5\% do seu faturamento em P\&D, de modo que, do referido valor pelo menos $2 \%$ deveriam obrigatoriamente ser aplicados em P\&D via convênios com universidades ou institutos de pesquisa relacionados. Na nova versão (Lei 10.176/01) inovações foram introduzidas, tais como: (a) incentivos de IPI com redução progressiva; (b) manutenção integral do incentivo para a ZFM (Zona Franca de Manaus); (c) criação do Fundo Setorial de Informática (CTInfo); (d) vantagens para as regiões Nordeste, Norte e CentroOeste; (e) isenção para pequenas e médias empresas; (f) fim da cumulatividade dos mecanismos da Lei dentro da cadeia produtiva; (g) melhor governança e transparência (PACHECO, 2007 apud RAPINI (2010); 4) as Leis 8.661/93 que dispunha sobre os incentivos fiscais para a capacitação tecnológica da indústria, por meio do Programa de Desenvolvimento Industrial (PDTI) e da agropecuária via Programa de Desenvolvimento Industrial Agropecuário (PDTA) e que foi revogada pela lei Lei ${ }^{\circ}$ 11.196, de $2005^{* *}$, e a Lei 9.532/97 que altera a legislação tributária federal; 5) a Lei 8.387/91, de incentivo para atividades de P\&D de empresas do setor de TICs localizadas na Zona Franca de Manaus; 6) a Lei ${ }^{\circ}$ 11.196, de 2005, ou Lei do Bem ${ }^{\dagger \dagger}$ que consolidou a política de incentivos às atividades de P\&D no país e aperfeiçoou os incentivos existentes, dando continuidade ao implementado na Lei no 10.637 de conceder os benefícios a qualquer empresa que realize atividade de P\&D (RAPINI, 2010;2013).

A par desta breve caracterização sobre as leis de incentivos fiscais, a tabela 03 evidencia que dentre as leis de incentivo fiscal, a Lei da informática é responsável por aproximadamente $70 \%$ dos valores totais de renúncia fiscal em cada ano. Segundo o relatório do Ministério de Ciência Tecnologia e Inovação, ${ }^{\dagger} \mathrm{em}$ 2006 o número de empresas que enviaram Prestação de Contas para uso dos benefícios da Lei do Bem foi de 130, ao passo que em 2014, o número de empresas atingiu valores da ordem de 1.206 empresas, de modo que em relação ao ano de 2013 , observou-se um crescimento em cerca de 4,15\%. Além disso, quando se analisa o tipo de investimento feito pelas empresas beneficiadas, observa-se que nos nove anos de usufruto da Lei do Bem, as empresas investiram em despesas de capital e de custeio valores superiores a $R \$ 60$ bilhões, ao passo que o valor total de renúncia fiscal do Governo Federal foi de aproximadamente 11,5 bilhões, ou cerca de $19 \%$ do total investido em PD\&I.

\footnotetext{
${ }^{* *}$ A lei n 11.196, de 2005 institui o Regime Especial de Tributação para a Plataforma de Exportação de Serviços de Tecnologia da Informação - REPES, o Regime Especial de Aquisição de Bens de Capital para Empresas Exportadoras - RECAP e o Programa de Inclusão Digital; dispõe sobre incentivos fiscais para a inovação tecnológica; altera o Decreto-Lei no 288 , de 28 de fevereiro de 1967, o Decreto no 70.235, de 6 de março de 1972, o Decreto-Lei no 2.287, de 23 de julho de 1986, as Leis nos 4.502, de 30 de novembro de 1964, 8.212, de 24 de julho de 1991, 8.245, de 18 de outubro de 1991, 8.387, de 30 de dezembro de 1991, 8.666, de 21 de junho de 1993, 8.981, de 20 de janeiro de 1995, 8.987, de 13 de fevereiro de 1995, 8.989, de 24 de fevereiro de 1995 , 9.249, de 26 de dezembro de 1995, 9.250, de 26 de dezembro de 1995, 9.311, de 24 de outubro de 1996, 9.317, de 5 de dezembro de 1996, 9.430, de 27 de dezembro de 1996, 9.718, de 27 de novembro de 1998, 10.336, de 19 de dezembro de 2001, 10.438, de 26 de abril de 2002, 10.485, de 3 de julho de 2002, 10.637, de 30 de dezembro de 2002, 10.755, de 3 de novembro de 2003, 10.833, de 29 de dezembro de 2003, 10.865, de 30 de abril de 2004, 10.925, de 23 de julho de 2004, 10.931, de 2 de agosto de 2004, 11.033, de 21 de dezembro de 2004, 11.051, de 29 de dezembro de 2004, 11.053, de 29 de dezembro de 2004, 11.101, de 9 de fevereiro de 2005, 11.128, de 28 de junho de 2005, e a Medida Provisória no 2.199-14, de 24 de agosto de 2001 ; revoga a Lei no 8.661, de 2 de junho de 1993, e dispositivos das Leis nos 8.668 , de 25 de junho de 1993, 8.981, de 20 de janeiro de 1995 , 10.637, de 30 de dezembro de 2002, 10.755, de 3 de novembro de 2003, 10.865, de 30 de abril de 2004, 10.931, de 2 de agosto de 2004, e da Medida Provisória no2.158-35, de 24 de agosto de 2001; e dá outras providências.

${ }^{++}$A Lei no 11.744, de setembro de 2008, alterou alguns dos dispositivos da "Lei do Bem" concernentes aos incentivos fiscais. Substituiu a depreciação acelerada pela depreciação integral na aquisição de máquinas, equipamentos, aparelhos e instrumentos novos a serem utilizados em atividades de inovação. Para mais detalhes ver RAPINI (2010).

‡¥ Para mais detalhes acesse: http://www.mct.gov.br/upd_blob/0239/239671.pdf
} 
Tabela 03: Valor da renúncia fiscal do governo federal segundo as leis de incentivo à pesquisa, desenvolvimento e capacitação tecnológica , 1990-2015

\begin{tabular}{|c|c|c|c|c|c|c|c|c|c|c|c|c|c|c|c|}
\hline \multirow[b]{2}{*}{ Anos } & \multicolumn{12}{|c|}{ Leis } & \multirow[b]{2}{*}{ Total } & \multirow[b]{2}{*}{$\%$} & \multirow[b]{2}{*}{ variação \% ao ano } \\
\hline & $\begin{array}{c}\text { Importação de } \\
\text { equipamentos } \\
\text { para pesquisa } \\
\text { pelo CNPq } \\
(8.010 / 90)\end{array}$ & $\%$ & $\begin{array}{c}\text { Isenção ou } \\
\text { redução de } \\
\text { impostos de } \\
\text { importação } \\
(8.032 / 90)\end{array}$ & $\%$ & \begin{tabular}{|c|} 
Lei de informática \\
$(8.248 / 91 \mathrm{e}$ \\
$10.176 / 01)^{(1)}$
\end{tabular} & $\%$ & $\begin{array}{c}\text { Capacitação } \\
\text { tecnológica da } \\
\text { ind. e da } \\
\text { agropecuária } \\
(8.661 / 93 \text { e } \\
9.532 / 97) \\
\end{array}$ & $\%$ & $\begin{array}{c}\text { Lei de informática } \\
\text { Zona Franca } \\
(8.387 / 91)\end{array}$ & $\%$ & $\begin{array}{l}\text { Lei do Bem } \\
(11.196 / 05)\end{array}$ & $\%$ & & & \\
\hline 1993 & $1.231,0$ & 16,9 & 197,0 & 2,7 & $5.838,0$ & 80,3 & - & - & - & - & - & - & $7.266,0$ & 100 & $2983 \%$ \\
\hline 1994 & $38.530,0$ & 17,2 & $3.306,0$ & 1,5 & $181.286,0$ & 80,9 & 906,0 & 0,4 & - & - & - & - & $\begin{array}{l}224.028,0 \\
\end{array}$ & 100 & $49 \%$ \\
\hline 1995 & $59.179,0$ & 17,7 & $9.220,0$ & 2,8 & $255.801,0$ & 76,6 & $9.686,0$ & 2,9 & - & - & - & - & $333.886,0$ & 100 & $63 \%$ \\
\hline 1996 & $57.680,0$ & 10,6 & $8.060,0$ & 1,5 & $405.604,0$ & 74,5 & $11.487,0$ & 2,1 & $61.827,0$ & 11,4 & - & - & $544.658,0$ & 100 & $33 \%$ \\
\hline 1997 & $61.330,0$ & 8,5 & $3.410,0$ & 0,5 & $542.605,0$ & 74,8 & $22.840,0$ & 3,1 & $95.490,0$ & 13,2 & - & - & $725.675,0$ & 100 & $31 \%$ \\
\hline 1999 & $78.956,0$ & 5,1 & $4.400,0$ & 0,3 & $1.054 .609,0$ & 67,9 & $33.700,0$ & 2,2 & $381.413,0$ & 24,6 & - & - & $1.553 .078,0$ & 100 & $-16 \%$ \\
\hline 2000 & $60.323,3$ & 4,6 & $10.521,6$ & 0,8 & $1.203 .659,6$ & 91,9 & $22.288,7$ & 1,7 & $13.374,1$ & 1,0 & - & - & $1.310 .167,3$ & 100 & $-84 \%$ \\
\hline 2001 & $118.417,8$ & 56,5 & $6.342,3$ & 3,0 & - & \begin{tabular}{|l|}
- \\
\end{tabular} & $22.446,8$ & 10,7 & $62.400,9$ & 29,8 & - & - & $209.607,8$ & 100 & $350 \%$ \\
\hline 2002 & $111.861,6$ & 11,8 & $6.516,7$ & 0,7 & $732.900,0$ & 77,6 & $15.220,5$ & 1,6 & $77.630,9$ & 8,2 & - & - & $944.129,7$ & 100 & $31 \%$ \\
\hline 2003 & $152.011,2$ & 12,3 & $8.201,4$ & 0,7 & $961.665,5$ & 77,6 & $19.668,1$ & 1,6 & $98.126,6$ & 7,9 & - & - & $1.239 .672,8$ & 100 & $-1 \%$ \\
\hline 2004 & $155.944,3$ & 12,7 & $11.427,7$ & 0,9 & $934.631,6$ & 76,1 & $37.120,4$ & 3,0 & $89.494,3$ & 7,3 & - & - & $1.228 .618,4$ & 100 & $33 \%$ \\
\hline 2005 & $182.611,3$ & 11,2 & $9.782,0$ & 0,6 & $1.300 .836,7$ & 79,8 & $35.314,6$ & 2,2 & $101.804,7$ & 6,2 & - & - & $1.630 .349,3$ & 100 & $63 \%$ \\
\hline 2006 & $183.435,4$ & 6,9 & $3.801,7$ & 0,1 & $2.038 .482,3$ & 76,5 & $102.834,2$ & 3,9 & $106.542,8$ & 4,0 & $227.859,4$ & 8,6 & $2.662 .955,7$ & 100 & $48 \%$ \\
\hline 2007 & $217.295,3$ & 5,5 & $5.727,5$ & 0,1 & $2.755 .400,2$ & 70,1 & $2.415,9$ & 0,1 & $81.611,2$ & 2,1 & $868.455,2$ & 22,1 & $3.930 .905,3$ & 100 & $36 \%$ \\
\hline 2008 & $385.516,0$ & 7,2 & $5.077,0$ & 0,1 & $3.261 .370,7$ & 60,8 & $1.312,8$ & 0,0 & $128.521,3$ & 2,4 & $1.582 .712,9$ & 29,5 & $5.364 .510,8$ & 100 & $-7 \%$ \\
\hline 2009 & $395.952,1$ & 7,9 & $2.077,7$ & 0,0 & $3.103 .252,0$ & 62,3 & 201,4 & 0,0 & $99.680,1$ & 2,0 & $1.382 .758,0$ & 27,7 & $4.983 .921,2$ & 100 & $17 \%$ \\
\hline 2011 & $341.906,2$ & 6,0 & $2.008,7$ & 0,0 & $3.771 .520,0$ & 66,5 & - & - & $143.421,7$ & 2,5 & $1.409 .983,9$ & 24,9 & $5.668 .840,3$ & 100 & $13 \%$ \\
\hline 2012 & $284.810,4$ & 4,4 & $2.252,9$ & 0,0 & $4.482 .200,0$ & 69,8 & - & - & $176.942,7$ & \begin{tabular}{|l|}
2,8 \\
\end{tabular} & $1.476 .804,1$ & 23,0 & $6.423 .010,0$ & 100 & $11 \%$ \\
\hline 2013 & $337.003,9$ & \begin{tabular}{|l|}
4,7 \\
\end{tabular} & $4.793,6$ & 0,1 & $4.934 .898,6$ & 69,3 & - & - & $206.056,3$ & \begin{tabular}{|l|}
2,9 \\
\end{tabular} & $1.636 .850,9$ & 23,0 & $7.119 .680,3$ & 100 & $-2 \%$ \\
\hline $2014^{(2)}$ & $353.582,6$ & 5,1 & $2.796,9$ & 0,0 & $4.580 .409,4$ & 66,0 & - & - & $219.668,4$ & 3,2 & $1.788 .163,5$ & 25,7 & $6.944 .695,1$ & 100 & $19 \%$ \\
\hline $2015^{(2)}$ & $413.916,8$ & 5,0 & $5.887,7$ & 0,1 & $5.709 .646,7$ & 69,0 & - & - & $254.319,4$ & 3,1 & $1.889 .626,4$ & 22,8 & $8.273 .474,2$ & 100 & - \\
\hline
\end{tabular}

\section{Fonte: Receita Federal do Brasil (RFB)}

Desta forma, dada as formas de apoio que dispõe o governo central, torna-se importante analizar a interação existente entre a oferta de benefícios fiscais, e a adesão por parte das empresas por intensidade tecnológica. Esse comportamento pode ser observado por meio da figura 01 para os triênios que englobam o período de 2001 a 2015. Ao se analisar o percentual de empresas que utilizaram o apoio governamental por intensidade tecnógica, observa-se que a partir de 2006 os setores de alta intensidade tecnológica buscaram usufruir mais intensamente dos benefícios advindos dos incentivos fiscais voltados para P\&D e para o financiamento à projetos com e sem parceria com universidades. Em outros termos, empresas dos setores de alta intensidade tecnológica pelo próprio caráter da atividade desempenhada, aproveitaram de forma mais intensa os incentivos fiscais proporcionados pelo Estado, indicando desta forma, que ações nesse sentido tendem colaborar para melhorar o esforço inovativo e fortalecer o Sistema Nacional de Inovação.

Entretanto, esse comportamento marcado pela maior próatividade das empresas em se beneficiar das renúncias, começa a se modificar à medida que analisamos setores caracterizados por menor intensidade tecnológica. No caso dos setores de média alta intensidade tecnológica, observa-se uma alteração relevante quanto à utilização das formas de apoio disponibilizadas pelo governo. Os setores caracterizados por serem de média alta intensidade tecnológica apresentaram taxas elevadas para incentivos voltados à aquisiçao de màquinas e equipamentos utilizados para inovar, ao passo que as demais opções disponíveis não apresentaram grande demanda por parte das empresas. Apesar desse comportamento modesto, a partir de 2006 observa-se um movimento de maior adesão de empresas no que se refere aos beneficios advindos dos incentivos fiscais voltados para $\mathrm{P} \& \mathrm{D}$, e para o financiamento à projetos com e sem parceria com as universidades. 
Figura 01: Percentual de empresas inovadoras que utilizaram apoio governamenal, total e por tipo de programa de apoio por intensidade tecnológica

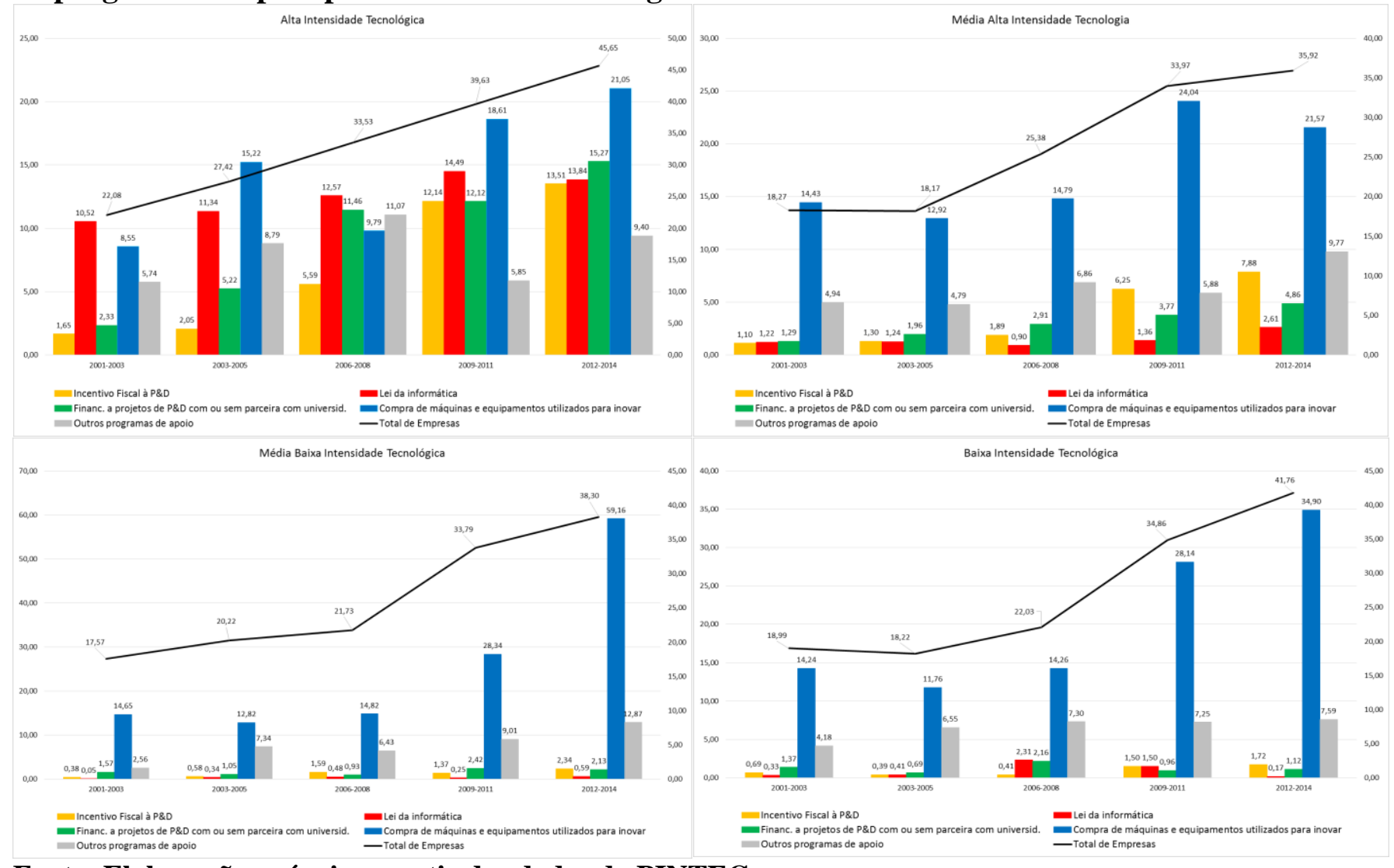

Fonte: Elaboração própria a partir dos dados da PINTEC

No que tange ao setores de média baixa e baixa intensidade tecnológica, constata-se que somente os incentivos voltados para compra de equipamentos para inovar mantiveram taxas elevadas ao longo do periodo em análise, em especial após o ano de 2009. Os dados sugerem que o tipo de apoio governamental voltado para incentivos as atividades de $\mathrm{P} \& \mathrm{D}$ e estreitamento das relações entre universidade e empresa para setores que produzem produtos de menor valor agregado não foram de grande interesse durante treze anos. Em outros termos, os setores de menor valor agregado da economia brasileira se mostraram pouco afeitos à busca por inovação, o que leva à necesidade de buscar entender as razões desse comportamento, que pode estar ligado às questões relacionadas às características do empresariado, tipo de relacionamento e informação de que se dispõe sobre projetos de pesquisa desenvolvidos nas universidades, dentre outras razões. A questão central é que os setores de média baixa e baixa intensidade tecnológica, veem ao longo de anos perdendo oportunidades advindas das redes de conhecimento proporcionadas pelas universidades e pelas pesquisas que poderiam ser realizadas em parcerias com as mesmas.

Assim posto, dado o comportamento das empresas no que tange à busca por apoio governamental expresso pela figura 01, torna-se relevante avaliar outro elemento da política implícita que corresponde ao financiamento da atividade produtiva. A abordagem pós keynesiana tem dedicado especial atenção à importância do sistema financeiro (Davidson, 1986; Minsky; 1986; Kregel, 1986; Carvalho, 1992) como instrumento essencial para a promoção do desenvolvimento, e da garantia de taxas elevadas de emprego e inovação. $\mathrm{O}$ acesso ao crédito brasileiro para o setor produtivo é balizado por meio da Taxa de Juros de Longo Prazo - TJLP do Banco de Desenvolvimento Econômico e Social - BNDES, por ser mais atrativa que a taxa Selic. Como podemos observar, pelo gráfico 06 temos a evolução da taxa Selic, de curto prazo, e da TJLP (taxa de juros de longo prazo) no período de 1994 a 2016. 


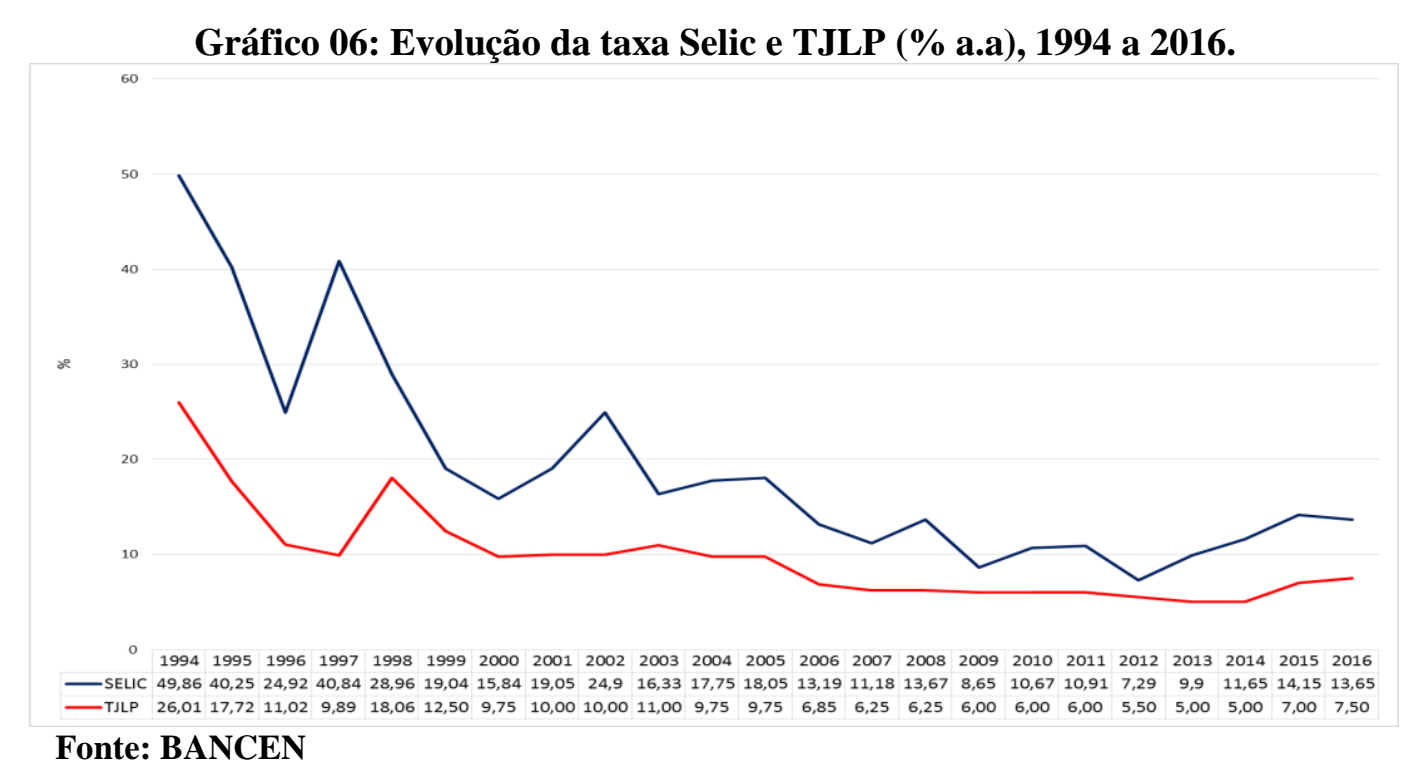

De modo geral, ambas as taxas foram mais elevadas, durante a década de 90, muito embora a partir dos anos 2000 apresentaram trajetória de queda mais consistente até o ano de 2012, para o caso da Selic e 2014 para a TJLP. A reversão da Selic a partir de 2012 ao assumir trajetória de elevação, reside na política do Banco Central de controlar o processo inflacioário que no período atingiu cerca de 5,83\% em 2012. Essa diretriz da estabilidade econômica tem suscitado um debate recorrente sobre a relação entre macroeconomia e política de C\&T\&I, na medida em que a taxa de juros não se limita em ser apenas um instrumento de política macroeconômica, mas como um dos instrumentos responsáveis pelo impacto no desempenho industrial de longo prazo. A questão é que para o avanço da C\&T\&I, requer-se estabilidade econômica como forma de mitigação da incerteza, de modo que o ambiente macroeconômico assume papel relevante (PACHECO, 2006). Todavia, como exposto por Carvalho et al. (2007) taxas de juros elevadas como é o caso da Selic, e utilizadas como único instrumento para a contenção do processo inflacionário, pode provocar uma situação onde as decisões de produção e investimento passam a dedicar maior peso às taxas de curto prazo, o que implica na inviabilidade do investimento. Por extensão os planos e projetos voltados para inovação também são afetados negativamente.

Assim posto, do ponto de vista do financiamento, ao longo de vinte e um anos, os setores que apresentaram as maiores participações na captação de recursos junto ao BNDES são aqueles classificados como média baixa e baixa intensidade tecnológica (gráfico 07 A e B), sendo estes conforme evidencia a figura 01, os setores que menos procuram buscar a inovação como aliada no aumento da competitividade e do esforço em endogeneizar o progresso técnico. Em média, estes setores foram responsáveis por 30\% ou mais dos desembolsos do BNDES ao longo do período em estudo. Considerando a taxa de crescimento dos desembolsos a partir do ano de 2004, observa-se uma trajetória positiva e mais intensa, com destaque para os setores de alta, média baixa e média alta intensidade tecnológica, de modo que atingiram em 2013 taxas de crescimento de aproximadamente $20 \% 16 \%$ e $11,5 \%$ respectivamente. Todavia, a partir desse ano os empréstimos para todos os setores por intensidade tecnológica sofreram desaceleração significativa, como consequência da necessidade de se fazer o ajuste das contas públicas, ante o alto déficit do setor público que já se avizinhava. Importante ressaltar que nessa fase de redução dos desembolsos, os setores de alta intensidade tecnológica foram aqueles cuja queda nos desembolsos foi mais acentuada, refletindo em certa medida a fragilidade destes setores, durante o período de expansão econômica. 
Gráfico 07: Desembolsos do BNDES por intensidade tecnológica, 1995 a 2016 (A) R \$ milhões e (B) ano base $(1995=1)$
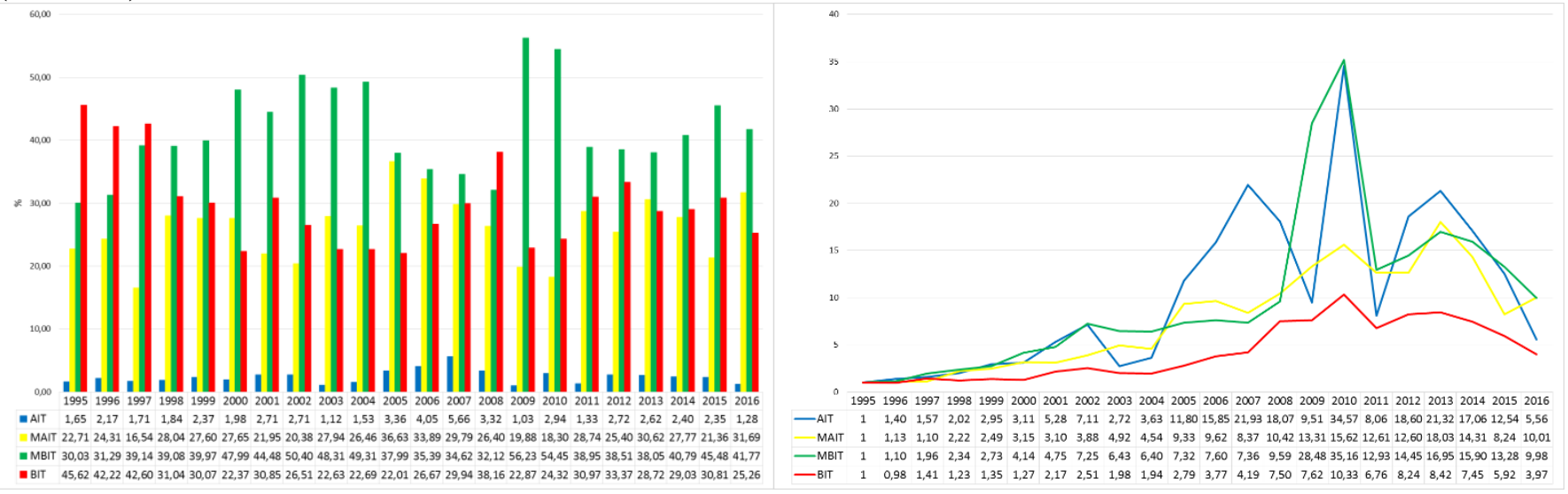

Fonte: BNDES

Desta forma, como a inserção internacional é essencial para investigar a posição relativa de um país, e sua dinâmica competitiva no comércio mundial, bem como em parte é resultado dos esforços de política econômica, (política macroeconomica e política industrial), podemos observar que, o esforço nacional não conseguiu alterar o histórico saldo comercial deficitário para produtos de média alta e alta intensidade tecnológica. Além disso, importante ressaltar que no Brasil, o período de 1994 a 1999 marca a fase do uso de uma âncora nominal como forma de estabilização dos preços, essencial para implantação do Plano Real. Nestes termos, a política monetária restritiva por parte do Banco Central, manifestou-se por vezes em sobrevalorização cambial e elevados déficits na balança comercial. Com a crise russa de 1998, gerou-se um nível de incerteza elevado nos mercado financeiros internacionais, e que diante da vulnerabilidade brasileira, passou-se a adotar o regime de câmbio flutuante, o que contribuiu para a ocorrência de grande volatilidade cambial ao longo dos anos posteriores.

\section{Gráfico 08: Saldo da balança comercial por intensidade tecnológica (bilhões R\$) e taxa de câmbio (R\$/US\$) - Brasil, 1997 - 2015.}

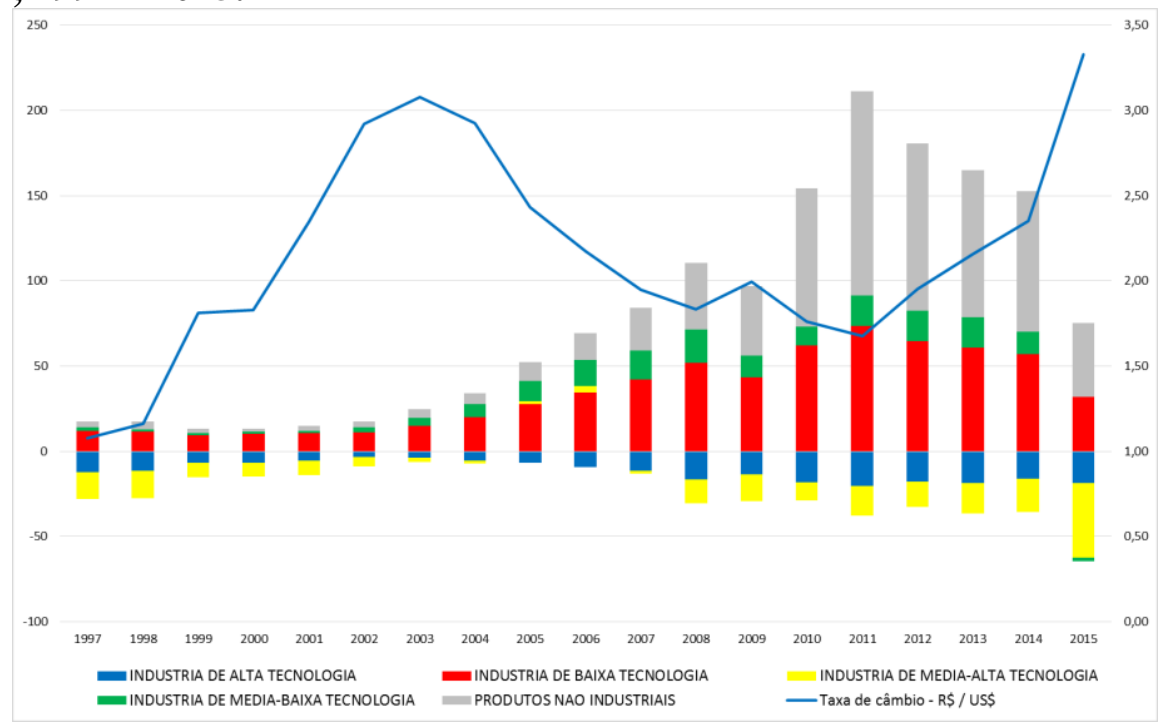

Fonte: SECEX/MDIC

Assim posto, dada a estratégia de política macroeconômica voltada para a maior flutuação do câmbio, associada ao uso da taxa de juros como único instrumento de controle da inflação, bem como a forma, e o tipo de setores que buscaram financiamento e incentivos tanto para investimento green field como para projetos de inovação, podemos considerar que a pauta de exportações brasileiras expressou uma estratégia de desenvolvimento pouco eficaz em fazer o país ganhar espaço no mercado internacional de bens de alto valor agregado. A trajetória porque passou a indústria brasileira nas últimas décadas, dada a 
competição internacional elevada, e intensificada via taxa de câmbio sobrevalorizada, contribuiu para a tendência à reprimarização, e o aprofundamento da tendência à desindustrialização, o que afetou negativamente o Brasil no quesito inovação e produção de bens de maior valor agregado como pode ser visto no gráfico 08. Ressalta-se que os períodos de maior apreciação cambial, que corresponderam aos anos de 1997-1998 e 2008-2011, foram aqueles cujos setores de maior intensidade apresentaram maior déficit. As atividades não industriais apresentaram superávits positivos nos períodos de maior apreciação cambial, sobretudo de 2009 a 2014. Associado ao fato de que as empresas que historicamente mais captam recursos são aquelas ligadas a setores de média baixa e baixa intensidade tecnológica, e que estas tenderam a ter pouca disposicão em investir em atividades de $\mathrm{P} \& \mathrm{D}$, e de interação com as universidades, salvo algumas exceções, fez com que a posição relativa internacional brasileira de exportador de bens primários e de baixo valor agregado se mantivesse ao longo do tempo.

\section{Considerações finais}

Do ponto de vista internacional, os dados sugerem que o Brasil caracterizou-se por ser um país marcado por taxas de crescimento instável do Produto Nacional ao longo das últimas décadas, e que vem sofrendo um processo de desindustrialização em curso, cuja tendência mostrou-se mais intensa a partir de meados da década de 90. Concomitantemente, o ritmo de inovação brasileiro, muito embora tenha apresentado evolução positiva, foi modesto quando comparado com os demais países em desenvolvimento. Em outros termos, o Brasil vem perdendo competitividade internacional em um quadro caracterizado pela perda de importância de sua indústria, e com baixa taxa de inovação, onde variáveis macroeconômicas (câmbio e juros) que expressam uma dimensão da política implícita são responsáveis por parcela importante desse resultado.

Ao se analisar os intrumentos de política implícita, observa-se duas tendências distintas, a saber: 1) comportamento passivo do Estado no que se refere ao dispêndio nacional em ciência e tecnologia (C\&T), ao dispêndio nacional em pesquisa e desenvolvimento (P\&D) e desembolsos do BNDES por intensidade tecnológica entre meados da década de 90 e início dos anos 2000, e; 2) comportamento mais ativo por parte do Estado quanto ao dispêndio nacional em ciência e tecnologia (C\&T), ao dispêndio nacional em pesquisa e desenvolvimento (P\&D) e desembolsos do BNDES por intensidade tecnológica entre meados da década de 2000 até o final série. Para o caso dos desembolsos do BNDES, evidenciou-se maior participação de empréstimos para setores de menor valor agregado, entre 1995 e 2016, sendo que estes mesmos setores correspondem àqueles que menos buscaram apoio governamental para o desenvolvimento de $\mathrm{P} \& \mathrm{D}$ e financiamento à projetos de pesquisa com ou sem a presença de universidades.

Nesse sentido, para o período pós meados da década de 2000, os dados sugerem que não faltou empenho por parte do Estado no uso dos instrumentos clássicos de politica implícita, tais como o financiamento ao investimento e à inovação, bem como incentivos fiscais com proteção à indústria de transformação. Todavia, as variáveis juros, e principalmente o câmbio mantiveram suas trajetórias sem os formuladores de política econômica levarem em conta os impactos na estrutura produtiva nacional. Portanto, a formulação de política macroeconômica que não inclua política industrial e de C\&T\&I, implica em efeitos positivos de curto prazo tanto no que tange ao controle inflacionário, e na redução do dispêndio com a dívida pública, porém tende a afetar negativamente o desempenho industrial e inovativo de longo prazo. Além disso, a análise dos dados sugere que a ausência de coordenação no manejo dos intrumentos implícitos também contribuiu para o modesto desempenho da C\&T\&I brasileira, na medida em que a oferta de crédito/financiamento atendeu setores de baixo valor agregado, e que além disso, em condições de câmbio desfavorável, o setor industrial se viu em condições desfavoráveis na competição internacional, passando a focar no mercado interno cujo estímulo à inovação é menor. Por fim, pelo saldo da balança comercial, entre 1997 e 2015, constata-se que o esforço de política industrial e de C\&T\&I despendido, não conseguiu surtir efeito significativo, haja visto que o país manteve a posição de exportador de commodities e de bens de baixo valor agregado.

\section{Referências:}

AGHION, Philippe et al. Rethinking industrial policy. Bruegel policy brief, v. 4, n. 11, 2011. 
ALBUQUERQUE, Eduardo da Motta. Sistema nacional de inovação no Brasil: uma análise introdutória a partir de dados disponíveis sobre a ciência e a tecnologia. Revista de Economia Política, v. 16, n. 3, p. 5672, 1996.

AREND, M. A industrialização do Brasil ante a nova divisão internacional do trabalho. In: IPEA. Presente e Futuro: desafios ao desenvolvimentismo brasileiro. IPEA, 2014.

BARBOSA FILHO, NELSON. O desafio macroeconômico de 2015-2018. Rev. Econ. Polit., São Paulo, v. 35, n. 3, p. 403-425, Sept. 2015. Disponível em: $<$ http://www.scielo.br/scielo.php?script=sci_arttext\&pid=S010131572015000300403\&1

ng=en\&nrm=iso>. Acesso em: 21 Out. 2016. http://dx.doi.org/10.1590/010131572015v35n03a02

BORRÁS, Susana; EDQUIST, Charles. The choice of innovation policy instruments. Technological forecasting and social change, v. 80, n. 8, p. 1513-1522, 2013.

CANO, Wilson; SILVA, Ana Lucia G. Política industrial do governo Lula. MAGALHÃES et al. Os, 2010. CARNEIRO, R. Crise, ajustamento e estagnação, a economia brasileira do período de 1974-89. Economia e Sociedade, v. 2, n. 1, p. 145-169, 2016.

CARNEIRO, R. Impasses do desenvolvimento brasileiro: a questão produtiva. Campinas: IE/UNICAMP, (Textos para Discussão n. 153), 2008.

CARNEIRO, R. Desenvolvimento em crise: a economia brasileira no último quarto do século XX. Unesp, 2002.

CARNEIRO, R. Desenvolvimento em crise: a economia brasileira no último quarto do século XX. Unesp, 2002.

CARVALHO, F.C. Mr. Keynes and the Post keynesians. Cheltenham: Edward Elgar, 1992.

CARVALHO, Fernando J. Expectativas, incerteza e convenções. Estratégias de desenvolvimento, política industrial e inovação: ensaios em memória de Fabio Erber. Rio de Janeiro: Banco Nacional de Desenvolvimento Econômico e Social, 2014.

CASSIOLATO, José Eduardo; LASTRES, Helena Maria Martins. Inovação, globalização e as novas políticas de desenvolvimento industrial e tecnológico. CASSIOLATO, José Eduardo; LASTRES, Helena Maria Martins. Globalização e inovação localizada: experiências de sistemas locais no Mercosul. Brasília: IBICT/MCT, 1998.

CHANG, Ha-Joon; AMSDEN, Alice H. The political economy of industrial policy. London: Macmillan, 1994.

CORDEN, Warner Max. Relationships between Macro-economic and Industrial Policies. The World Economy, v. 3, n. 2, p. 167-184, 1980.

CORONEL, Daniel. Política industrial e desenvolvimento econômico: a reatualiação de um debate histórico. Revista de Economia Política, v. 34, n. 1, p. 103, 2014.

COUTINHO, L. A especialização regressiva: um balanço do desempenho industrial pósestabilização. Brasil: desafios de um país em transformação. Rio de Janeiro: José Olympio, p. 84-115, 1997.

COUTINHO, Luciano G. et al. Regimes macroeconômicos e estratégias de negócios: uma política industrial alternativa para o Brasil no século XXI. Lastres HMM, Cassiolato JE, Arroio A, organizadores. Conhecimento, sistemas de inovação e desenvolvimento. Rio de Janeiro: Contraponto, p. 429-48, 2005.

DAVIDSON, P. Finance, funding, saving, and investment. Journal of Post Keynesian Economics, v. 9, n. 1, p. 101-110, 1986.

DE ALMEIDA, Julio Gomes. Alcance e lacunas da nova política industrial. 2011.

EDQUIST, Charles. Innovation policy: A systemic approach. Tema, Univ., 1999.

ERBER, Fábio S.; CASSIOLATO, José Eduardo. Política industrial: teoria e prática no Brasil e na OCDE. Revista de Economia Política, v. 17, n. 2, p. 66, 1997.

GONÇALVES, R. Competitividade internacional e integração regional: a hipótese da inserção regressiva. Revista de Economia Contemporânea, v. 5, Edição Especial. 2001.

GUERRA, Oswaldo. Política industrial e competitividade: de Collor a FHC. Organizações \& Sociedade, v. 4, n. 8, p. 39-56, 1997.

JOHNSON, Chalmers A. The industrial policy debate. Ics Pr, 1984. 
KALDOR, N. Causes of the slow rate of economic growth of the United Kingdom. Cambridge University Press. 1966.

KREGEL, J. A note on finance, liquidity, saving, and investment. Journal of Post Keynesian Economics, v. 9, n. 1, p. 91-100, 1986.

KRUGMAN, P.R. (1989). Industrial organization and international trade. In: SCHMALENSEE, R.;WILLIG, R. (Eds.). Handbook of industrial organization. New York: Elsevier.

KRUGMAN, Paul. The current case for industrial policy. Protectionism and world welfare, p. 160-179, 1993.

KUPFER, D. Política industrial. Econômica, Rio de Janeiro, v. 5, n. 2, p.91-108, dez. 2003. Disponível em: http://www.ie.ufrj.br/gic/intranet/trabalhos/publicacoes/politica_industrial_revista_economica.pdf.

Acesso em: 10 mar. 2017.

LAPLANE, M.; SARTI, F. Prometeu Acorrentado: o Brasil na indústria mundial no início do século XXI. Política Econômica em Foco, n. 7, p. 271-291, 2006.

MINSKY, P. H. Can 'It' Happen Again? Essays on Instability and Finance. Armonk. New York: M.E. Sharpe, 1982.

NASSIF, André et al. National innovation system and macroeconomic policies: Brazil and India in comparative perspective. United Nations Conference on Trade and Development, 2007.

PACHECO, Carlos Américo; ALMEIDA, JG de. A política de inovação. texto para Discussão, n. 210, 2013.

PALMA, José Gabriel (2005). Quatro fontes de "desindustrialização" e um novo conceito de "doença holandesa". Trabalho apresentado na Conferência de Industrialização, Desindustrialização e Desenvolvimento, organizada pela FIESP e IEDI. Centro Cultural da FIESP, 28 de Agosto de 2005.

PESSOTI, B. C; PESSOTI, G. C. A indissociável relação entre indústria, desenvolvimento econômico e políticas indústrias no Brasil. RDE - Revista de Desenvolvimento Econômico. Ano XI _ No 19, Janeiro de 2009 Salvador, BA. 2009

PRATES, D. M., A inserção externa da economia brasileira no governo Lula. Política Econômica em Foco, n. 7, seção IV, nov.2005/abr.2006. Campinas: NEIT/IE/UNICAMP. 2006.

RAPINI, M. O financiamento aos investimentos em inovação no Brasil. 2010. 146 f. 2010. Tese de Doutorado. Tese (Doutorado em Economia)-Instituto de Economia, Universidade Federal do Rio de Janeiro, Rio de Janeiro, 2010.

RAPINI, Marcia et al. Padrão de financiamento aos investimentos em inovação no Brasil. Cedeplar, Universidade Federal de Minas Gerais, 2013.

RATTNER, Henrique. Aspectos da política tecnológica nos países da América Latina. Revista de Administração de Empresas, v. 21, n. 3, p. 15-27, 1981.

REINER, Christian; STARITZ, Cornelia. Private sector development and IndustrIal PolIcy: why, how and for whom?. Private Sector Development, p. 53, 2013.

RODRIK, D. A volta da política industrial. 2010. Disponível em: http://www2.senado.leg.br/bdsf/bitstream/handle/id/461130/noticia.htm?sequence=1 Acesso: 05/mar.

2017

RODRIK, Dani. The return of industrial policy. project Syndicate, v. 12, 2010.

RODRIK, Dani. Unconditional convergence. National Bureau of Economic Research, 2011.

ROWTHORN, R. e COUTTS, K. Commentary: Deindustrialisation and the balance of payments in advanced economies. Cambridge Journal of Economics. vol. 28, no. 5, 767-790. 2004.

ROWTHORN, R.; RAMASWAMY, R. Deindustrialization: causes and implications. International Monetary Fund, Staff Studies for the Economic Outlook, pp.61-77, December, 1997.

ROWTHORN, R.; RAMASWAMY, R. Growth, trade, and deindustrialization. IMF Staff papers, p. 1841, 1999.

SAGASTI, F. Ciencia y tecnología para el desarrollo: informe comparativo central del proyecto sobre Instrumentos de Política Científica y Tecnológica (STPI). Bogotá, Centro Internacional de Investigaciones para el Desarrollo (CIID), 1978.

SARTI, F.; HIRATUKA, C. Desenvolvimento industrial no Brasil: oportunidades e desafios futuros. Campinas: IE. Unicamp, (Texto para discussão n. 187) 2011. 
SCHAPIRO, Mario G. Ativismo estatal e industrialismo defensivo: instrumentos e capacidades na política industrial brasileira. 2013.

SOUZA, N. J. Desenvolvimento Econômico. 4. ed. São Paulo: Editora Atlas, 242p, 1999.

SUZIGAN, W. Situação atual da indústria brasileira e implicações para a política industrial. Planejamento e Políticas Públicas, Rio de Janeiro, n. 6, 1991.

SUZIGAN, W.; VILLELA, A. Industrial Policy in Brazil. Campinas: UNICAMP, 1997.

SUZIGAN, Wilson et al. Política industrial e desenvolvimento. Revista de economia política, v. 26, n. 2, p. $102,2006$.

TREGENNA, Fiona. Characterising deindustrialisation: An analysis of changes in manufacturing employment and output internationally. Cambridge Journal of Economics, v. 33, n. 3, p. 433-466, 2009. 